\title{
Modeling of Atmospheric-Pressure Dielectric Barrier Discharges in Argon with Small Admixtures of Tetramethylsilane
}

\author{
Detlef Loffhagen $^{1}$ (D) . Markus M. Becker ${ }^{1}$ (D) - Andreas K. Czerny ${ }^{2,3}$ (D) . \\ Claus-Peter Klages ${ }^{2}$ iD
}

Received: 30 June 2020 / Accepted: 19 August 2020 / Published online: 7 October 2020

(C) The Author(s) 2020

\begin{abstract}
A time-dependent, spatially one-dimensional fluid-Poisson model is applied to analyze the impact of small amounts of tetramethylsilane (TMS) as precursor on the discharge characteristics of an atmospheric-pressure dielectric barrier discharge (DBD) in argon. Based on an established reaction kinetics for argon, it includes a plasma chemistry for TMS, which is validated by measurements of the ignition voltage at the frequency $f=86.2 \mathrm{kHz}$ for TMS amounts of up to $200 \mathrm{ppm}$. Details of both a reduced Ar-TMS reaction kinetics scheme and an extended plasma-chemistry model involving about 60 species and 580 reactions related to TMS are given. It is found that good agreement between measured and calculated data can be obtained, when assuming that $25 \%$ of the reactions of TMS with excited argon atoms with a rate coefficient of $3.0 \times 10^{-16} \mathrm{~m}^{3} / \mathrm{s}$ lead to the production of electrons due to Penning ionization. Modeling results for an applied voltage $U_{\mathrm{a}, 0}=4 \mathrm{kV}$ show that TMS is depleted during the residence time of the plasma in the DBD, where the percentage consumption of TMS decreases with increasing TMS fraction because only a finite number of excited argon species is available to dissociate and/or ionize the precursor via energy transfer. Main species resulting from that TMS depletion are presented and discussed. In particular, the analysis clearly indicates that trimethylsilyl cations can be considered to be mainly responsible for the film formation.
\end{abstract}

Keywords Dielectric barrier discharges $\cdot$ Tetramethylsilane $\cdot$ Numerical modeling $\cdot$ Plasma polymerization

Detlef Loffhagen

loffhagen@inp-greifswald.de

1 Leibniz Institute for Plasma Science and Technology, Felix-Hausdorff-Str. 2, 17489 Greifswald, Germany

2 Institute for Surface Technology, Technische Universität Braunschweig, Bienroder Weg 54 E, 38108 Braunschweig, Germany

3 Present Address: Institute of Applied Materials - Applied Material Physics, Karlsruhe Institute of Technology, Herrmann-von-Helmholtz-Platz 1, 76344 Eggenstein-Leopoldshafen, Germany 


\section{Introduction}

Tetramethylsilane (TMS, $\left.\left(\mathrm{CH}_{3}\right)_{4} \mathrm{Si}\right)$, one of the most simple organosilicon compound (organosilane, alkylsilane), has frequently been used as a precursor for plasma-enhanced chemical vapor deposition (PECVD) of silicon- and carbon-containing thin films [1-11]. The deposition process is also termed "plasma polymerization"- and the deposits "plasma polymer"-if a relatively large "organic" character of the precursor (monomer) is retained in the film, observable, e.g., as a major content of $\mathrm{CH}_{\mathrm{x}}$ moeities. Aside from other potential purposes, TMS-derived thin films have been of interest as insulators with low dielectric constants for microelectronic applications ("low-k films") [7-9, 11]. TMS is also a major reaction product in processing plasmas fed with more complex organosilicon monomers such as hexamethyldisiloxane (HMDSO) [12-14]. Owing to its low boiling point of only $300 \mathrm{~K}$ [15], TMS is an extremely flammable liquid, its vapor forming explosive mixtures with air. Taking into account the corresponding hazards of working with TMS is of special importance for atmospheric-pressure plasma processes.

Thin film deposition from TMS has usually been performed by means of low-temperature discharge plasmas at low pressure. In addition to the plasma polymerization in pure TMS vapor [2, 6, 7, 11, 16, 17], TMS-vapor mixtures diluted by $\operatorname{Ar}[3,4,10,18-20]$, $\mathrm{O}_{2}[7,9,11], \mathrm{O}_{2}$ and $\mathrm{Ar}$ [9], and $\mathrm{SiH}_{4}$ with $\mathrm{N}_{2} \mathrm{O}$ as the oxidant gas [8] were investigated experimentally. Few of these experimental studies were assisted by theoretical and modeling analyzes. By employing the general convective diffusion equation, a simple analytical expression of the deposition rate in Ar-TMS mixtures was obtained in [4]. Furthermore, preliminary modeling of the electrical discharge of a capacitively coupled, low-frequency device in low-pressure Ar-TMS mixtures based on a one-dimensional fluid model was reported in $[19,20]$.

The deposition of thin functional films using PECVD at atmospheric pressure has gained great scientific and technical interest during the last two decades [21, 22]. In contrast to low-pressure techniques, suffering from high costs of equipment and difficult integration into in-line production processes [23], atmospheric-pressure systems avoid the need for expensive vacuum equipment, allow easier and continuous processing, and make it even possible to treat materials and geometries, which are difficult to handle at reduced pressure conditions.

Atmospheric-pressure plasma polymerization of TMS has recently been performed using different discharge configurations. A radio-frequency glow-discharge system was applied in [24] to generate organic-inorganic hybrid coatings in a plasma generated with a TMS precursor concentration of $0.01-0.04 \mathrm{vol} \%$ in He carrier gas. An atmospheric-pressure plasma jet in He with a few vol. \% TMS was used in [25-29] to improve the surface hydrophobicity of imitation leather with polyester surface. Furthermore, Haq et al. [30] recently used an atmospheric-pressure microplasma reactor fed by an Ar-TMS mixture containing up to $3500 \mathrm{ppm}$ TMS to study its dissociation for the growth of SiC nanocrystals.

While plasma jets are especially developed for a localized treatment, dielectric barrier discharges (DBDs) are more suitable for the treatment of larger surfaces and they have widely been applied as a source for PECVD processes [31]. A new kind of reactor for plasma treatments based on DBDs, involving a gradient mixer and a homogenizer in the gas-supply line to enable a concentration gradient of the percursor or another relevant gas species oriented perpendicular to the flow direction, was presented in [32] and tested using plasma polymerization of several precursors including mixtures of Ar (or Ar mixed with $2 \% \mathrm{Xe}$ ) and small amounts of up to about $750 \mathrm{ppm}$ of TMS vapor. 
The present paper deals with the analysis of atmospheric-pressure DBDs in argon with small amounts of TMS as precursor by means of numerical modeling. It refers to the plane-parallel discharge configuration with lateral gas flow injection described in [33]. The time-dependent, spatially one-dimensional fluid-Poisson model takes into account the spatial variation of the discharge plasma between plane-parallel dielectrics covering the electrodes. It is based on the DBD model for argon reported in [34], which has been extended by collision processes for the precursor gas TMS and resulting reaction procucts. The basic reaction kinetics scheme includes 26 collision processes of TMS as well as further 16 reactions related to collisions of the trimethylsilyl cation $\left(\left(\mathrm{CH}_{3}\right)_{3} \mathrm{Si}^{+}\right)$and anion $\left(\left(\mathrm{CH}_{3}\right)_{3} \mathrm{Si}^{-}\right)$, respectively.

The analysis concerns the electrical characteristics of the DBD at first. The studies aim to clarify the impact of small TMS admixtures added to the carrier gas Ar on the ignition behavior as well as on the temporal evolution of discharges at conditions typical of deposition experiments. In particular, the impact of Penning ionization processes of excited argon atoms with TMS molecules is investigated since they can play a significant role for the electron production in atmospheric-pressure plasmas and can influence the ignition and burning voltage of such discharges [21,35]. Furthermore, it is analyzed how the trimethylsilyl anions, resulting from the dissociative electron attachment to TMS, influence the discharge behavior.

Measurements of the ignition voltage of DBDs in argon with TMS admixtures of up to $200 \mathrm{ppm}$ supplement these numerical studies. The total rate coefficient of collisions between excited argon atoms and TMS is determined by comparing measured and calculated ignition voltages. This comparison also provides information about the contribution of the Penning ionization and the quenching of excited argon atoms by monomer molecules, leading to the dissociation of TMS into neutral reaction products.

Secondly, model calculations for operating conditions typical of deposition experiments are presented and discussed. For these calculations, the basic reaction kinetics scheme of TMS has been extended by about 540 additional collision processes involving further 56 species. That makes it possible to also get information about the behavior of, e.g., the primary radicals trimethylsilyl $\left(\left(\mathrm{CH}_{3}\right)_{3} \mathrm{Si}\right)$ and methyl $\left(\mathrm{CH}_{3}\right)$ as well as other radical species, further stable molecules, such as hexamethyldisilane $\left(\left(\mathrm{CH}_{3}\right)_{3} \mathrm{SiSi}\left(\mathrm{CH}_{3}\right)_{3}\right)$, trimethylsilane $\left(\left(\mathrm{CH}_{3}\right)_{3} \mathrm{SiH}\right)$ or methane $\left(\mathrm{CH}_{4}\right)$ and ethane $\left(\mathrm{C}_{2} \mathrm{H}_{6}\right)$, or other positive and negative charge carriers. Details of this extended reaction kinetics scheme are given, and selected results of corresponding modeling studies are represented and discussed. The analysis includes a comparison of measured and calculated discharge currents as well as a comprehensive representation of key species generated in the DBD during the residence time of the gas in the discharge area as predicted by numerical modeling. In addition, the impact of ionic species on the film deposition in plasma polymerization is discussed.

\section{Description of the Model}

The modeling studies presented in this paper are related to the plane-parallel DBD configuration used in [33] for electrical measurements. A schematic representation of the plasma reactor is shown in Fig. 1a. The DBD was ignited between two rectangular electrodes with a width of $8 \mathrm{~cm}$ and a length in flow direction of $1 \mathrm{~cm}$ corresponding to a discharge area $A=8 \mathrm{~cm}^{2}$. Both electrodes were made of steel mesh glued onto borofloat glass dielectrics with a thickness $\Delta$ of $2 \mathrm{~mm}$ and a relative permittivity $\varepsilon_{\mathrm{r}}$ of 4.6. The gap width $d$ was 


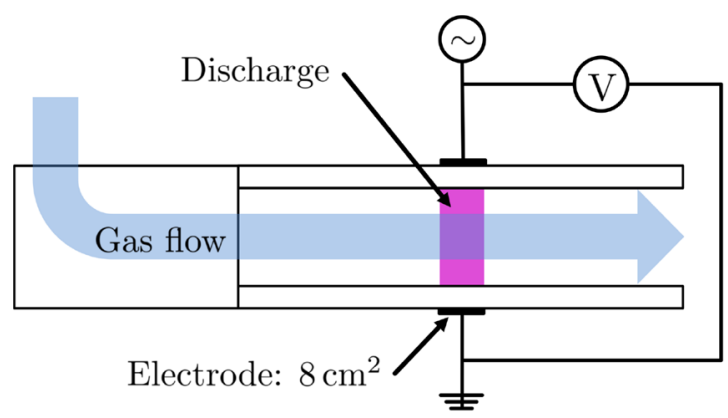

(a)

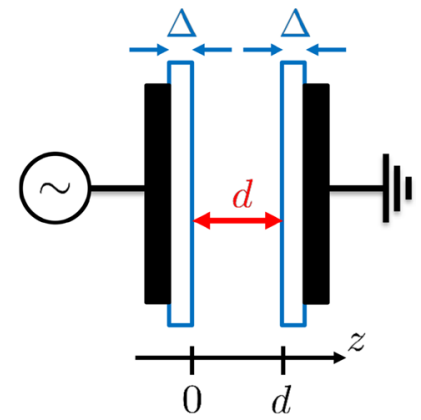

(b)

Fig. 1 Schematic drawing of the plasma reactor, a with the discharge area $A=8 \mathrm{~cm}^{2}$ and of the spatially one-dimensional discharge geometry, b with gap width $d$ and thickness of dielectric layers $\Delta$

$1 \mathrm{~mm}$. A high-voltage (HV) generator was used to power the discharge by the sinusoidal voltage

$$
U_{\mathrm{a}}(t)=U_{\mathrm{a}, 0} \sin (2 \pi f t)
$$

with the amplitude $U_{\mathrm{a}, 0}$ at a frequency $f$ of $86.2 \mathrm{kHz}$.

A schematic representation of the corresponding discharge geometry used in the modeling studies is displayed in Fig. 1b. The time-dependent, spatially one-dimensional model considers the axial component $z$ of the plasma between the plane-parallel, dielectric covered electrodes, where the electrode on the left side is powered by the voltage (1) and that to the right is grounded. Such a spatially one-dimensional treatment is well suited for the analysis of DBDs operating in the homogeneous or glow mode [36] and was successfully applied for the analysis of DBDs, e.g., in Ar [34], Ar-HMDSO mixtures [35, 37], $\mathrm{N}_{2}$ with $0.1 \mathrm{vol} \% \mathrm{O}_{2}$ [38], and $\mathrm{CO}_{2}[39]$.

\section{Basic Relations}

The fluid model comprises balance equations for the densities $n_{j}$ of relevant neutral particles and charge carriers as well as for the electron energy density $n_{\mathrm{e}} u_{\mathrm{e}}$, the Poisson equation to determine the electric potential $\Phi$ and field $E$, as well as a balance equation for the surface charge density $\sigma_{\mathrm{s}}$ to consider the accumulation of charge carriers on the dielectric surfaces at $z_{0}=0$ and $z_{0}=d$. A schematic representation of the basic relations and the sequence of their solution is shown in Fig. 2. Here $e_{0}, \varepsilon_{0}$ and $Z_{j}$ are the elementary charge, vacuum permittivity and particle charge number, respectively, $E_{\mathrm{D}}$ denotes the electric field inside the respective dielectric barrier, $v=-1$ at $z_{0}=0$ and $v=1$ at $z_{0}=d$.

The fluxes $\Gamma_{j}$ of heavy particles are calculated in the common drift-diffusion approximation, while the particle flux $\Gamma_{\mathrm{e}}$ and energy flux $Q_{\mathrm{e}}$ of electrons are determined by the improved drift-diffusion approximation introduced by Becker et al. [40, 41]. $S_{j}$ represents the gain and loss of particles of kind $j$ in the plasma due to collision processes and radiative transitions, and $\tilde{S}_{\mathrm{e}}$ denotes the gain and loss of electron energy caused by the various collision processes involving electrons. 


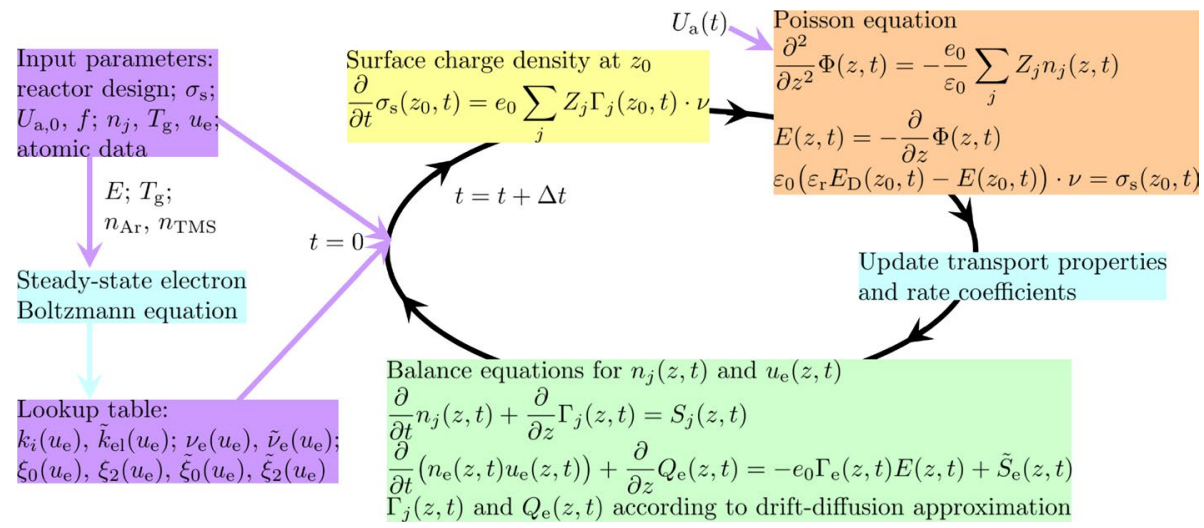

Fig. 2 Sketch of the time-dependent, spatially one-dimensional fluid model with time step size $\Delta t$

Regarding the electrons, their rate coefficients $k_{i}$ of the different inelastic collision processes with heavy particles and their energy rate coefficient $\tilde{k}_{\mathrm{el}}$ for elastic collisions were obtained by solving the steady-state, spatially homogeneous Boltzmann equation for given reduced electric field $E / N$ with the background gas density $N$, gas temperature $T_{\mathrm{g}}$, Ar-TMS mixture ratio, and atomic data, using the electron collision cross sections specified in "Reaction Kinetics Schemes" section. The solution of this electron kinetic equation was done by means of a generalized version of the solution method [42] adapted to take into account non-conservative electron collision processes [43]. It also yields the dissipation frequencies $v_{\mathrm{e}}$ and $\tilde{\nu}_{\mathrm{e}}$ as well as the transport coefficients $\xi_{0}, \xi_{2}, \tilde{\xi}_{0}$, and $\tilde{\xi}_{2}$ of the electrons [41]. Afterwards, lookup tables for these coefficients and frequencies as a function of the mean electron energy $u_{\mathrm{e}}$ were generated for the respective mixture ratio of Ar and TMS and were used in the fluid model calculations. Further details about the basic relations, the boundary conditions and the solution method are given in [35]. In particular, flux boundary conditions are employed at the dielectric surfaces when solving the particle balance equations, where stable molecules related to the TMS kinetics are assumed to be completely reflected while radical species are not reflected. That is, the latter stick and/or recombine on the surface $[20,44]$.

\section{Reaction Kinetics Schemes}

The reaction kinetics for Ar-TMS mixtures is based on the argon model reported in [34]. The reaction kinetics scheme for argon takes into account ground state argon atoms $\left(\operatorname{Ar}\left[1 \mathrm{p}_{0}\right]\right.$ in Paschen notation), metastable $\left(\operatorname{Ar}\left[1 \mathrm{~s}_{5}\right]\right.$ and $\left.\operatorname{Ar}\left[1 \mathrm{~s}_{3}\right]\right)$ and resonance $\left(\operatorname{Ar}\left[1 \mathrm{~s}_{4}\right]\right.$ and $\left.\operatorname{Ar}\left[1 \mathrm{~s}_{2}\right]\right)$ atoms, lumped excited states $\operatorname{Ar}[2 \mathrm{p}]$ and $\operatorname{Ar}\left[2 \mathrm{p}^{\prime}\right]$, a summarized higher excited atomic level $\operatorname{Ar}[\mathrm{hl}]$, excimers $\operatorname{Ar}_{2}\left[{ }^{3} \Sigma_{\mathrm{u}}^{+}, \mathrm{v}=0\right], \operatorname{Ar}_{2}\left[{ }^{1} \Sigma_{\mathrm{u}}^{+}, \mathrm{v}=0\right], \operatorname{Ar}_{2}\left[{ }^{3} \Sigma_{\mathrm{u}}^{+}, \mathrm{v} \gg 0\right]$ and $\mathrm{Ar}_{2}\left[{ }^{1} \Sigma_{\mathrm{u}}^{+}, \mathrm{v} \gg 0\right]$ in the vibrational ground $(\mathrm{v}=0)$ and highly vibrationally excited $(\mathrm{v} \gg 0)$ states with the energy levels $9.76 \mathrm{eV}, 9.84 \mathrm{eV}, 11.37 \mathrm{eV}$ and $11.45 \mathrm{eV}$, respectively, as well as the atomic $\left(\mathrm{Ar}^{+}\right)$and molecular $\left(\mathrm{Ar}_{2}^{+}\right)$ion. These 14 heavy particle components and the electrons are subject to 114 reactions including 70 electron collision processes, 24 heavy particle collision processes, and 20 radiative transitions. This argon model was extended by including relevant collision processes for small amounts of the precursor gas TMS. Following [35], the electrical characteristics of atmospheric-pressure DBDs in argon with small 
monomer admixtures can be determined by the collision processes of TMS with electrons and argon species as well as of the primary ions generated. This basic reaction kinetics model related to TMS is listed in Table 1.

The electron collision processes of TMS include elastic collisions, two vibrational excitations with the energy losses 0.11 and $0.27 \mathrm{eV}$, a total electronic excitation with the energy loss $7.45 \mathrm{eV}$, leading to the dissociation into the trimethylsilyl and the methyl radical [20], a total ionization with the energy loss $9.8 \mathrm{eV}$, resulting in the trimethylsilyl cation and a methyl radical, as well as the dissociative electron attachment, leading to the formation of

Table 1 Collision processes related to TMS included in the basic reaction kinetics model in addition to the argon model reported in [34]

\begin{tabular}{|c|c|c|c|}
\hline Index & Reaction & Rate coefficient & References \\
\hline \multicolumn{4}{|c|}{ Elastic electron collisions } \\
\hline 1 & $\left(\mathrm{CH}_{3}\right)_{4} \mathrm{Si}+\mathrm{e} \rightarrow\left(\mathrm{CH}_{3}\right)_{4} \mathrm{Si}+\mathrm{e}$ & $f\left(u_{\mathrm{e}}\right)$ & [45] \\
\hline \multicolumn{4}{|c|}{ Electron impact excitation and dissociation } \\
\hline 2 & $\left(\mathrm{CH}_{3}\right)_{4} \mathrm{Si}+\mathrm{e} \rightarrow\left(\mathrm{CH}_{3}\right)_{4} \mathrm{Si}\left[\mathrm{v}_{1}\right]+\mathrm{e}$ & $f\left(u_{\mathrm{e}}\right)$ & [45] \\
\hline 3 & $\left(\mathrm{CH}_{3}\right)_{4} \mathrm{Si}+\mathrm{e} \rightarrow\left(\mathrm{CH}_{3}\right)_{4} \mathrm{Si}\left[\mathrm{v}_{2}\right]+\mathrm{e}$ & $f\left(u_{\mathrm{e}}\right)$ & {$[45]$} \\
\hline 4 & $\left(\mathrm{CH}_{3}\right)_{4} \mathrm{Si}+\mathrm{e} \rightarrow\left(\mathrm{CH}_{3}\right)_{3} \mathrm{Si}+\mathrm{CH}_{3}+\mathrm{e}$ & $f\left(u_{\mathrm{e}}\right)$ & {$[20,45]$} \\
\hline \multicolumn{4}{|c|}{ Electron impact ionization and detachment } \\
\hline 5 & $\left(\mathrm{CH}_{3}\right)_{4} \mathrm{Si}+\mathrm{e} \rightarrow\left(\mathrm{CH}_{3}\right)_{3} \mathrm{Si}^{+}+\mathrm{CH}_{3}+2 \mathrm{e}$ & $f\left(u_{\mathrm{e}}\right)$ & [46] \\
\hline 6 & $\left(\mathrm{CH}_{3}\right)_{3} \mathrm{Si}^{-}+\mathrm{e} \rightarrow\left(\mathrm{CH}_{3}\right)_{3} \mathrm{Si}+2 \mathrm{e}$ & $f\left(u_{\mathrm{e}}\right)$ & [47-49] \\
\hline \multicolumn{4}{|c|}{ Dissociative electron attachment } \\
\hline 7 & $\left(\mathrm{CH}_{3}\right)_{4} \mathrm{Si}+\mathrm{e} \rightarrow\left(\mathrm{CH}_{3}\right)_{3} \mathrm{Si}^{-}+\mathrm{CH}_{3}$ & $f\left(u_{\mathrm{e}}\right)$ & [45] \\
\hline \multicolumn{4}{|c|}{ Ion-molecule reactions } \\
\hline 8 & $\mathrm{Ar}^{+}+\left(\mathrm{CH}_{3}\right)_{4} \mathrm{Si} \rightarrow\left(\mathrm{CH}_{3}\right)_{3} \mathrm{Si}^{+}+\mathrm{CH}_{3}+\mathrm{Ar}\left[1 \mathrm{p}_{0}\right]$ & $1.5 \times 10^{-15}$ & {$[36,50]$} \\
\hline 9 & $\mathrm{Ar}_{2}^{+}+\left(\mathrm{CH}_{3}\right)_{4} \mathrm{Si} \rightarrow\left(\mathrm{CH}_{3}\right)_{3} \mathrm{Si}^{+}+\mathrm{CH}_{3}+2 \mathrm{Ar}\left[1 \mathrm{p}_{0}\right]$ & $1.2 \times 10^{-15}$ & {$[36,50]$} \\
\hline \multicolumn{4}{|c|}{ Quenching of excited argon species leading to Penning ionization } \\
\hline $10-16$ & $\mathrm{Ar}^{*}+\left(\mathrm{CH}_{3}\right)_{4} \mathrm{Si} \rightarrow \quad\left(\mathrm{CH}_{3}\right)_{3} \mathrm{Si}^{+}+\mathrm{CH}_{3}+\mathrm{Ar}\left[1 \mathrm{p}_{0}\right]+\mathrm{e}$ & $k_{\mathrm{M}, \mathrm{Ar}^{*}}^{\mathrm{Pl}}$ & See text \\
\hline \multicolumn{4}{|c|}{ Quenching of excited argon species leading to neutral products } \\
\hline $17-23$ & $\mathrm{Ar}^{*}+\left(\mathrm{CH}_{3}\right)_{4} \mathrm{Si} \rightarrow\left(\mathrm{CH}_{3}\right)_{3} \mathrm{Si}+\mathrm{CH}_{3}+\mathrm{Ar}\left[1 \mathrm{p}_{0}\right]$ & $k_{\mathrm{M}, \mathrm{Ar}^{*}}^{\mathrm{Q}}$ & See text \\
\hline $24-27$ & $\mathrm{Ar}_{2}^{*}+\left(\mathrm{CH}_{3}\right)_{4} \mathrm{Si} \rightarrow\left(\mathrm{CH}_{3}\right)_{3} \mathrm{Si}+\mathrm{CH}_{3}+2 \mathrm{Ar}\left[1 \mathrm{p}_{0}\right]$ & $k_{\mathrm{M}, \mathrm{Ar}^{*}}$ & $\begin{array}{l}\text { Analogous } \\
\text { to } \operatorname{Ar}^{*}[51,52]\end{array}$ \\
\hline \multicolumn{4}{|c|}{ Electron-ion recombination } \\
\hline 28 & $\left(\mathrm{CH}_{3}\right)_{3} \mathrm{Si}^{+}+\mathrm{e} \rightarrow\left(\mathrm{CH}_{3}\right)_{2} \mathrm{Si}+\mathrm{CH}_{3}$ & $1.8 \times 10^{-12} \times\left(T_{\mathrm{e}} / 300\right)^{-0.5}$ & {$[53,54]$; see text } \\
\hline \multicolumn{4}{|c|}{ Collisional detachment of electrons } \\
\hline $29-35$ & $\mathrm{Ar}^{*}+\left(\mathrm{CH}_{3}\right)_{3} \mathrm{Si}^{-} \rightarrow\left(\mathrm{CH}_{3}\right)_{3} \mathrm{Si}+\mathrm{Ar}\left[1 \mathrm{p}_{0}\right]+\mathrm{e}$ & $5.9 \times 10^{-16}$ & {$[36,55]$} \\
\hline $36-39$ & $\mathrm{Ar}_{2}^{*}+\left(\mathrm{CH}_{3}\right)_{3} \mathrm{Si}^{-} \rightarrow\left(\mathrm{CH}_{3}\right)_{3} \mathrm{Si}+2 \mathrm{Ar}\left[1 \mathrm{p}_{0}\right]+\mathrm{e}$ & $5.9 \times 10^{-16}$ & {$[36,55]$} \\
\hline \multicolumn{4}{|c|}{ Ion-ion recombination } \\
\hline 40 & $\mathrm{Ar}^{+}+\left(\mathrm{CH}_{3}\right)_{3} \mathrm{Si}^{-} \rightarrow\left(\mathrm{CH}_{3}\right)_{3} \mathrm{Si}+\mathrm{Ar}[\mathrm{hl}]$ & $1.1 \times 10^{-13}$ & [56] \\
\hline 41 & $\mathrm{Ar}_{2}^{+}+\left(\mathrm{CH}_{3}\right)_{3} \mathrm{Si}^{-} \rightarrow\left(\mathrm{CH}_{3}\right)_{3} \mathrm{Si}+\mathrm{Ar}\left[2 \mathrm{p}^{\prime}\right]+\mathrm{Ar}\left[1 \mathrm{p}_{0}\right]$ & $8.7 \times 10^{-14}$ & [56] \\
\hline 42 & $\left(\mathrm{CH}_{3}\right)_{3} \mathrm{Si}^{+}+\left(\mathrm{CH}_{3}\right)_{3} \mathrm{Si}^{-} \rightarrow 2\left(\mathrm{CH}_{3}\right)_{3} \mathrm{Si}$ & $8.9 \times 10^{-14}$ & [56] \\
\hline
\end{tabular}

The rate coefficients are given in $\mathrm{m}^{3} / \mathrm{s}$. Rate coefficients $f\left(u_{\mathrm{e}}\right)$ are obtained from the solution of the electron Boltzmann equation as a function of the mean electron energy $u_{\mathrm{e}}$ using the cross section data of the reference given. $T_{\mathrm{e}}=2 u_{\mathrm{e}} /\left(3 k_{\mathrm{B}}\right)$ is the electron temperature in $\mathrm{K}$, and $T_{\mathrm{g}}=300 \mathrm{~K}$. $\operatorname{Ar}^{*}$ denotes $\operatorname{Ar}\left[1 \mathrm{~s}_{5 . .2}\right]$, $\operatorname{Ar}[2 \mathrm{p}], \operatorname{Ar}\left[2 \mathrm{p}^{\prime}\right]$, and $\operatorname{Ar}[\mathrm{hl}]$ as well as $\operatorname{Ar}_{2}^{*}$ abbreviates $\operatorname{Ar}_{2}\left[{ }^{3} \Sigma_{\mathrm{u}}^{+}, \mathrm{v}=0\right], \operatorname{Ar}_{2}\left[{ }^{1} \Sigma_{\mathrm{u}}^{+}, \mathrm{v}=0\right], \operatorname{Ar}_{2}\left[{ }^{3} \Sigma_{\mathrm{u}}^{+}, \mathrm{v} \gg 0\right]$, and $\mathrm{Ar}_{2}\left[{ }^{1} \Sigma_{\mathrm{u}}^{+}, \mathrm{v} \gg 0\right]$ 
the trimethylsilyl anion and $\mathrm{CH}_{3}$. The corresponding electron collision cross sections are given in $[45,46]$.

Furthermore, collision processes of TMS with atomic and molecular argon ions as well as with excited argon atoms and molecules are taken into account. Here, the Langevin capture rate coefficient [36] is used for ion-molecule reactions, where the polarizability of TMS is $11.04 \times 10^{-30} \mathrm{~m}^{3}$ [50].

Regarding collision processes of TMS with excited argon atoms and molecules, the information in the literature is diverse. Experimental investigations on TMS dissociation processes in plasmas provide rate coefficients $k_{\mathrm{M}, \mathrm{Ar}^{*}}$ for the reaction of the monomer with the metastable atom $\operatorname{Ar}\left[1 \mathrm{~s}_{5}\right.$ ] ranging from $6.0 \times 10^{-18}$ to $2.2 \times 10^{-17} \mathrm{~m}^{3} / \mathrm{s}$ [57]. When comparing these values with those for collisions of excited argon atoms with several atoms and molecules reported in [51] and that for $\operatorname{Ar}\left[1 \mathrm{~s}_{5}\right.$ ] collisions with HMDSO [58], the rate coefficient $k_{\mathrm{M}, \mathrm{Ar}^{*}}$ is expected to be larger by a factor of 10 at least. In particular, when using the hard sphere cross section approach with a collision radius of $2.725 \times 10^{-10} \mathrm{~m}$ for $\operatorname{Ar}\left[1 \mathrm{~s}_{5}\right.$ ] [51] and the van-der-Waals radius for TMS [50] of $2.92 \times 10^{-10} \mathrm{~m}$, a rate coefficient $k_{\mathrm{M}, \mathrm{Ar}^{*}}$ of about $5 \times 10^{-16} \mathrm{~m}^{3} / \mathrm{s}$ results. Furthermore, Jauberteau et al. [57] state that collisions of $\operatorname{Ar}\left[1 s_{5}\right]$ with TMS mainly lead to the formation of neutral radicals. However, Penning ionization should take place, because the energy of excited argon atoms is large enough to ionize TMS. In particular, the fraction $\alpha_{\mathrm{Pl}}$ leading to Penning ionization was measured to be 0.06 for collisions of argon metastables with TMS and 0.5 for collisions of argon metastables with trimethylsilane $\left(\left(\mathrm{CH}_{3}\right)_{3} \mathrm{SiH}\right)$ in [59].

In order to clarify this situation, the determination of the rate coefficient $k_{\mathrm{M}, \mathrm{Ar}^{*}}$ and the Penning ionization fraction $\alpha_{\mathrm{Pl}}$ with $0 \leq \alpha_{\mathrm{Pl}} \leq 1$ as well as an analysis of their impact on modeling results are part of the present studies. Thus, the Penning ionization reaction

$$
\mathrm{Ar}^{*}+\left(\mathrm{CH}_{3}\right)_{4} \mathrm{Si} \stackrel{k_{\mathrm{M}, \mathrm{Ar}}^{\mathrm{Pl}}}{\longrightarrow}\left(\mathrm{CH}_{3}\right)_{3} \mathrm{Si}^{+}+\mathrm{CH}_{3}+\mathrm{Ar}\left[1 \mathrm{p}_{0}\right]+\mathrm{e}
$$

with the rate coefficient $k_{\mathrm{M}, \mathrm{Ar}^{*}}^{\mathrm{Pl}}=\alpha_{\mathrm{Pl}} k_{\mathrm{M}, \mathrm{Ar}^{*}}$ and the quenching process

$$
\mathrm{Ar}^{*}+\left(\mathrm{CH}_{3}\right)_{4} \mathrm{Si} \stackrel{k_{\mathrm{M}, \mathrm{Ar} *}^{\mathrm{Q}}}{\longrightarrow}\left(\mathrm{CH}_{3}\right)_{3} \mathrm{Si}+\mathrm{CH}_{3}+\mathrm{Ar}\left[1 \mathrm{p}_{0}\right]
$$

with the rate coefficient $k_{\mathrm{M}, \mathrm{Ar}^{*}}^{\mathrm{Q}}=\left(1-\alpha_{\mathrm{Pl}}\right) k_{\mathrm{M}, \mathrm{Ar}^{*}}$ are considered in the reaction kinetics scheme for every excited atomic species, abbreviated by Ar*. In reaction (2), the TMS molecule is dissociated into a trimethylsilyl ion, a methyl radical and an electron, which gets most of the excess energy, and the quenching process (3) results in a trimethylsilyl and a methyl radical. In addition, the quenching of TMS by argon excimers is considered leading to the formation of trimethylsilyl, methyl and two argon ground state atoms. Following [52], the corresponding rate coefficient is assumed to equal the rate coefficient $k_{\mathrm{M}, A r^{*}}$ for reactions of the monomer with excited argon atoms.

Reactions of the trimethylsilyl cation $\left(\mathrm{CH}_{3}\right)_{3} \mathrm{Si}^{+}$comprise the electron-ion recombination and the ion-ion mutual neutralization due to the interaction with $\left(\mathrm{CH}_{3}\right)_{3} \mathrm{Si}^{-}$. The recombination of $\left(\mathrm{CH}_{3}\right)_{3} \mathrm{Si}^{+}$by electron impact leads to the formation of a dimethylsilylene $\left(\left(\mathrm{CH}_{3}\right)_{2} \mathrm{Si}\right)$ and a methyl radical [60]. The corresponding thermal reaction rate coefficient at $300 \mathrm{~K}$ is assumed to be similar to that of the HMDSO cation given in [53] and the dependence on the electron temperature $T_{\mathrm{e}}=2 u_{\mathrm{e}} /\left(3 k_{\mathrm{B}}\right)$ with the Boltzmann constant $k_{\mathrm{B}}$ is approximated according to [54]. The rate coefficients for the mutual neutralization of the negative trimethylsilyl ion $\left(\mathrm{CH}_{3}\right)_{3} \mathrm{Si}^{-}$due to interaction with the positive ions $\mathrm{Ar}^{+}, \mathrm{Ar}_{2}^{+}$, and $\left(\mathrm{CH}_{3}\right)_{3} \mathrm{Si}^{+}$were derived from the approximate scaling formula 
proposed by Hickman [56]. The electron impact detachment cross section of $\left(\mathrm{CH}_{3}\right)_{3} \mathrm{Si}^{-}$ with an energy loss of $0.971 \mathrm{eV}$ [61] was obtained by scaling from the classical ionization model of Thomson [62] as discussed in [47, 63] using the cross sections for detachment from $\mathrm{H}^{-}$for energies $U<10 \mathrm{eV}$ and from $\mathrm{C}^{-}$for larger energies given in [48, 49]. Furthermore, detachment processes of $\left(\mathrm{CH}_{3}\right)_{3} \mathrm{Si}^{-}$due to collisions with excited argon atoms and molecules are taken into account. The corresponding rate coefficient was estimated by means of the Langevin formula for ion-molecule reactions [36], using the polarizability of argon of $1.64 \times 10^{-30} \mathrm{~m}^{3}$ [55]. Moreover, the mobilities of the trimethylsilyl ions times background gas density were estimated by use of the polarization mobility [64] obtained from the Langevin theory and amount to $5.7 \times 10^{21}(\mathrm{~V} \mathrm{~m} \mathrm{~s})^{-1}$ for the gas mixtures under consideration. The corresponding diffusion coefficient was calculated using Einstein's relation [36].

The reaction kinetics set in Table 1 does not provide information about the spatio-temporal behavior of the radicals trimethylsilyl $\left(\left(\mathrm{CH}_{3}\right)_{3} \mathrm{Si}\right)$, dimethylsilylene $\left(\left(\mathrm{CH}_{3}\right)_{2} \mathrm{Si}\right)$, and methyl $\left(\mathrm{CH}_{3}\right)$ as well as other neutral species and charge carriers. Further collision processes, which are included in an extended reaction kinetics scheme related to TMS, are given Table 2. This extended set of reactions takes into account the collision processes of the neutral species listed in Table 3 and ions given in Table 4. Table 3 also specifies the masses, enthalpies of formation, electron affinities, ionization potentials, and polarizabilities of the neutral species.

Regarding the electron impact ionization processes of the organosilicon species in Table 2, collision cross sections were calculated by application of the modified additivity rule of Deutsch et al. [65], using the collision cross sections for carbon [66], hydrogen [67], and silicon [68, 69]. The electron-impact cross sections of various hydrocarbons and hydrogen- or carbon-containing species leading to ionization, attachment or dissociation as well as the electron detachment cross sections of $\mathrm{H}^{-}$and $\mathrm{CH}_{2}^{-}$were taken from the literature given in Table 2. The rate coefficients of most ion-molecule reactions were determined by Langevin formula [36] using the polarizabilities given in Table 3.

Collision processes of excited argon atoms and molecules with different neutral species can lead to dissociation into neutral fragments and/or to Penning ionization. The rate coefficients and the fraction of dissociation or Penning ionization for the collision processes of the organosilicon species were estimated in accordance with the collision processes of TMS or HMDSO. For the corresponding reactions with hydrocarbons or hydrogen molecules the rate coefficients provided by the references given in Table 2 were employed in general.

The rate coefficients of the electron recombination due to collisions with organosilicon ions were estimated to have a typical value of $1.0 \times 10^{-12} \mathrm{~m}^{3} / \mathrm{s}$ at $T_{\mathrm{e}}=300 \mathrm{~K}$ with a dependence on $T_{\mathrm{e}}$ approximated according to [54]. The corresponding rate coefficients and branching ratios for the hydrocarbon ions and $\mathrm{H}_{2}^{+}$were generally taken from the literature.

Except for the $\mathrm{H}^{+}-\mathrm{H}^{-}$reaction, the rate coefficients of the ion-ion recombination processes were calculated by means of the scaling formula given by Hickman [56]. The compilation of neutral-neutral reactions at the end of Table 2 includes collision processes with two-body rate coefficients larger than $1.0 \times 10^{-18} \mathrm{~m}^{3} / \mathrm{s}$ only, where the rate coefficients originate from the references given in Table 2. Notice that collision processes of the 16 neutral reaction products pentamethyl[(trimethylsilyl)methyl]disilane, octamethyltrisilane, 1,1,1,2,2,3,3-heptamethyltrisilane, bis(trimethylsilyl)methane, ethylpentamethyldisilane, 1,1,2,2-tetramethyldisilane, 1,3-dimethyl-1,3-disilabicyclo[1.1.0]butane, ethyltrimethylsilane, 1,1-dimethylsilirane, 1,1-dimethylsilirene, ethynylsilane, n-butane, 1-butene, 1,3-butadiene, propane, and propene specified in Table 3 are neglected. 


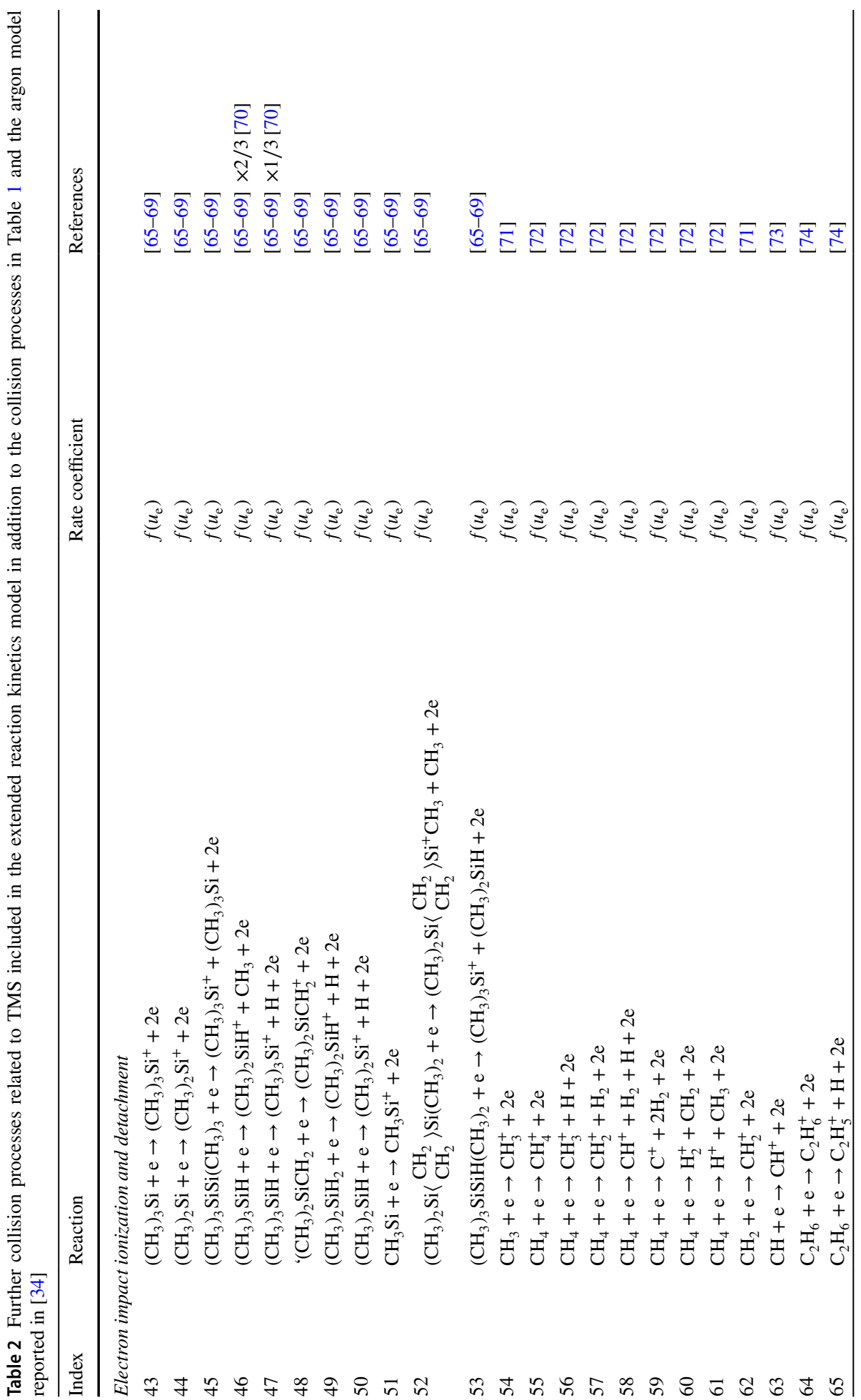




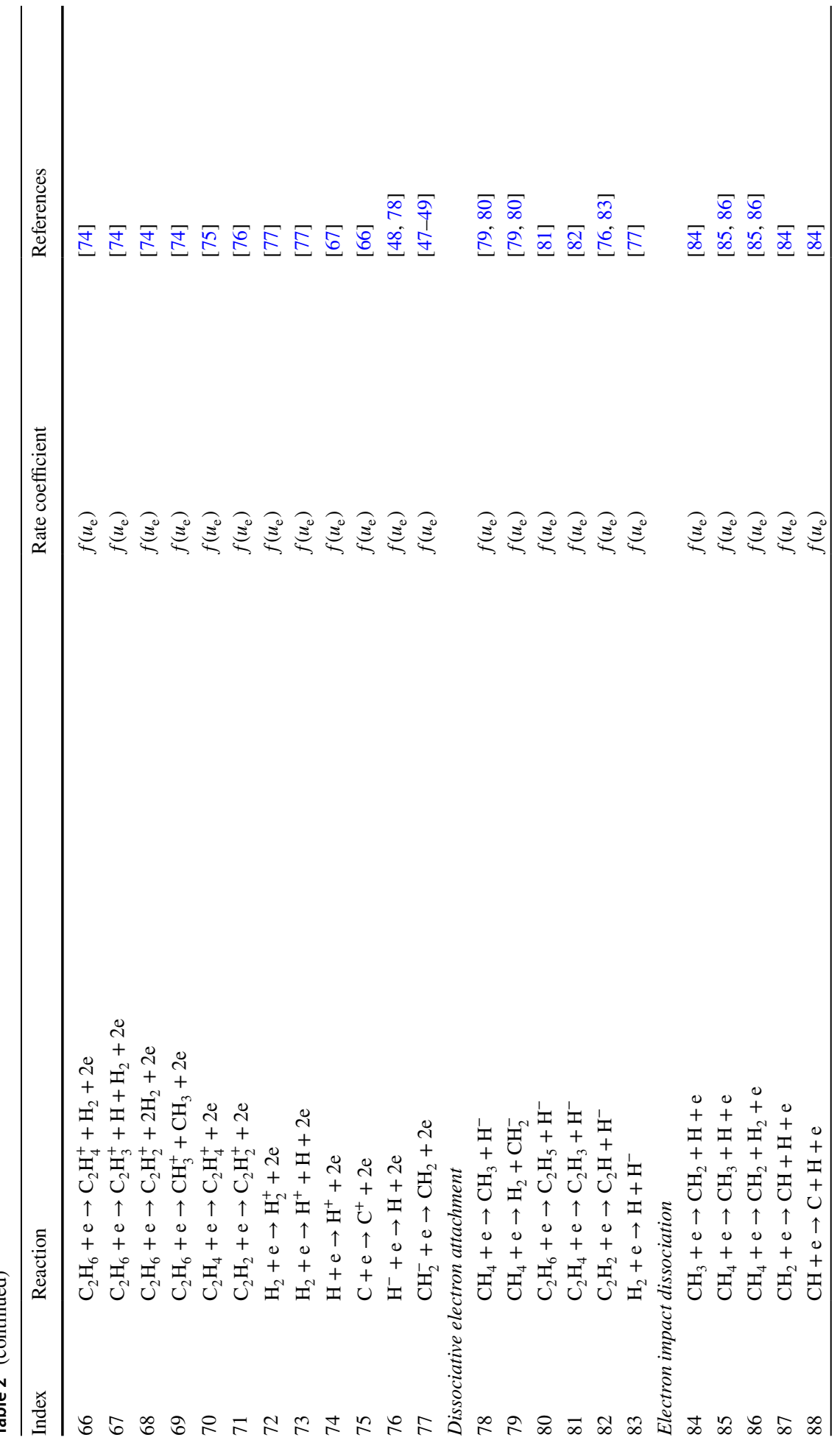




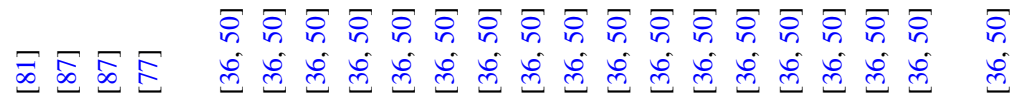

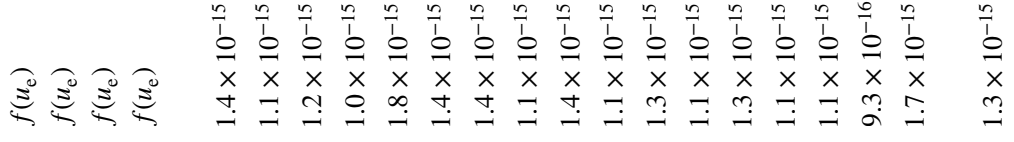

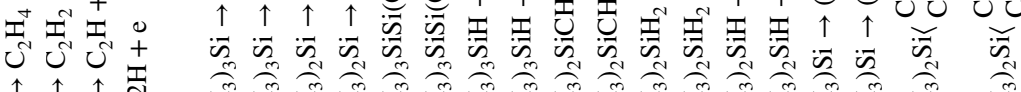




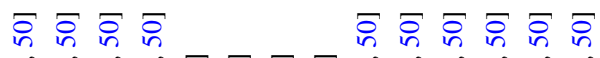

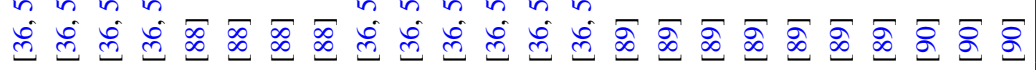

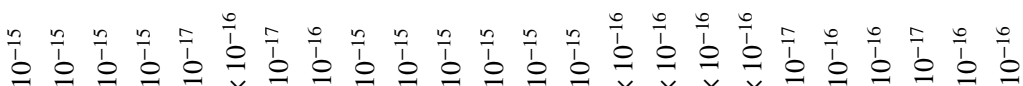

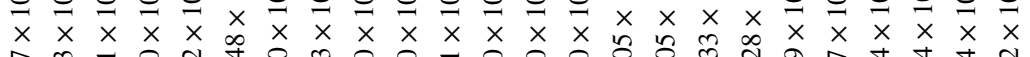

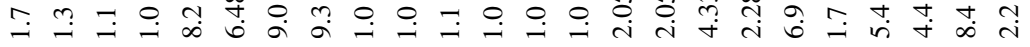

$\underset{2}{2}$

安

$+ \pm$

零

胥

$++$

$+\frac{+}{4}+\frac{1}{4}$

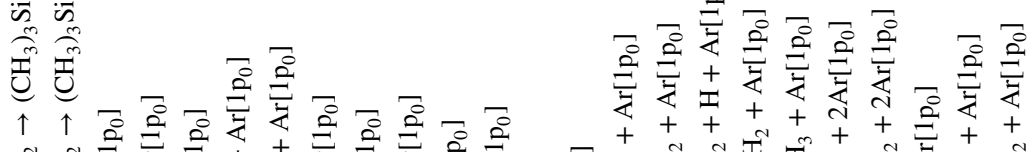

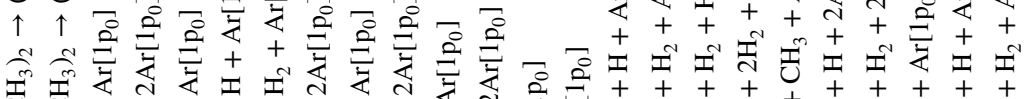

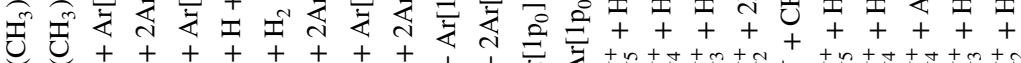
己

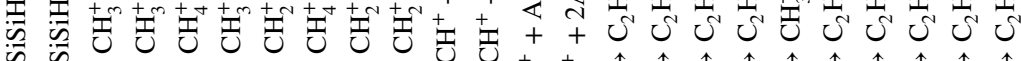

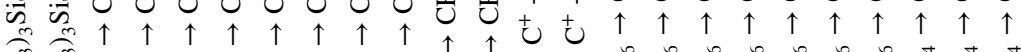

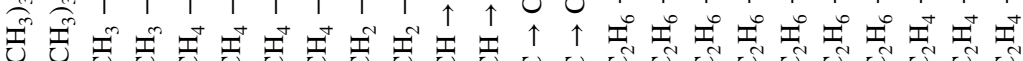

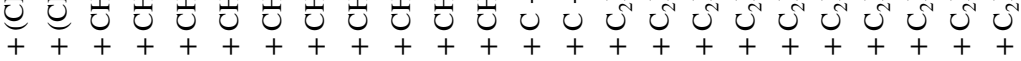

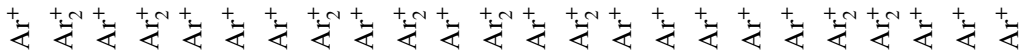

$\frac{\sqrt{\frac{0}{0}}}{\frac{0}{\overparen{2}}}$

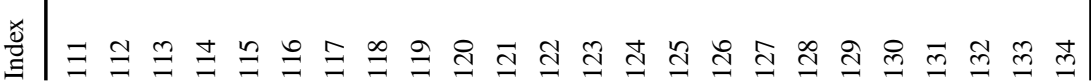

\section{Springer}




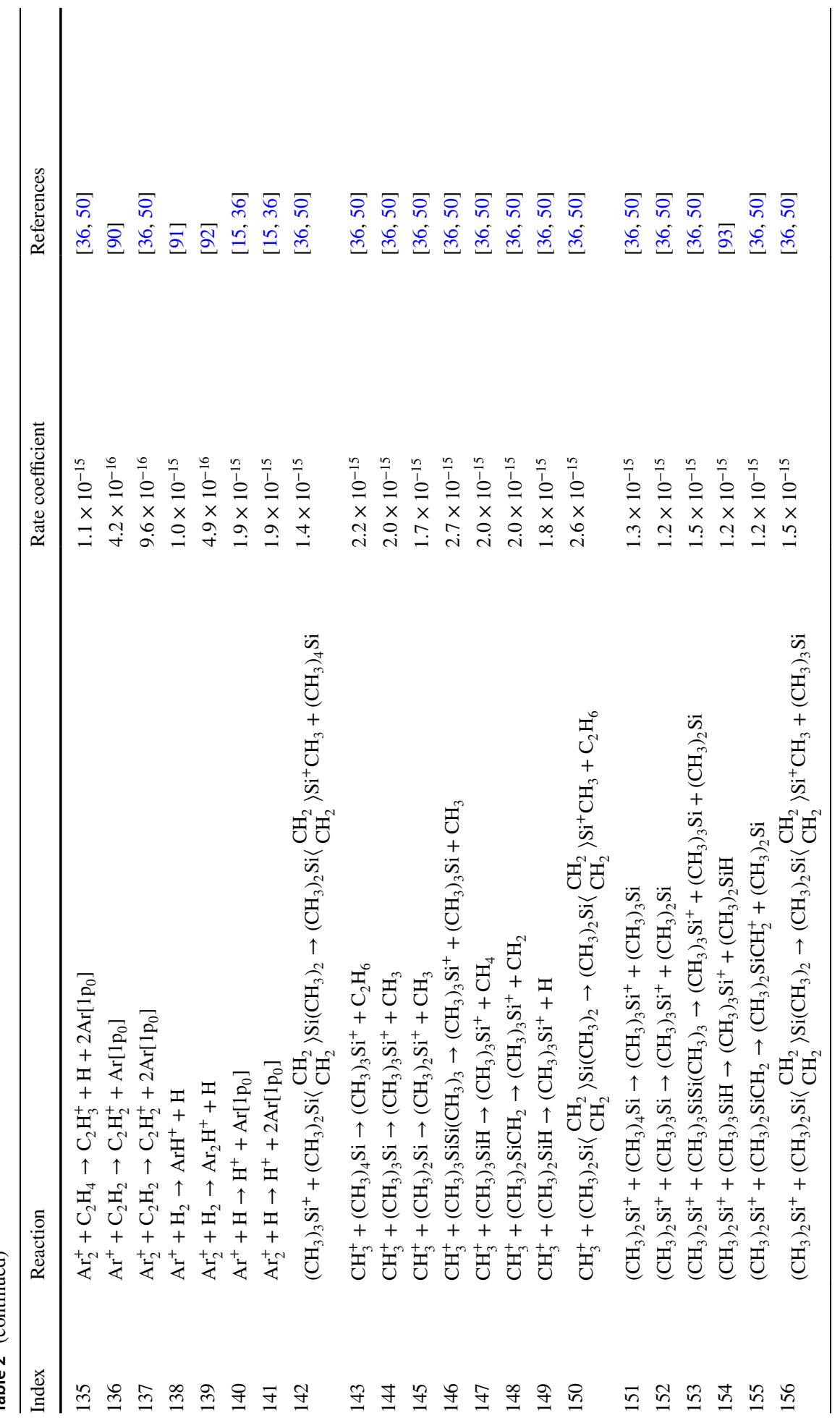




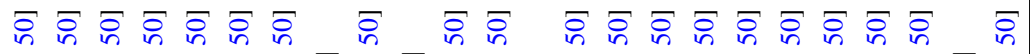

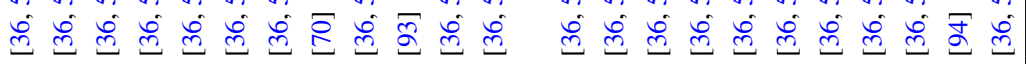

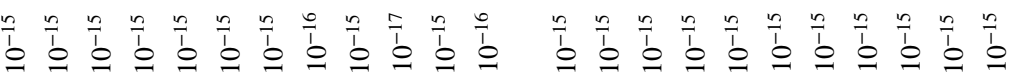

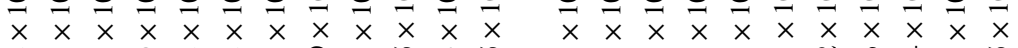

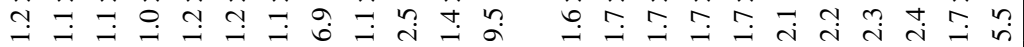

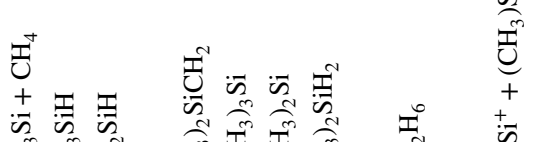<smiles>[C-]#C</smiles>

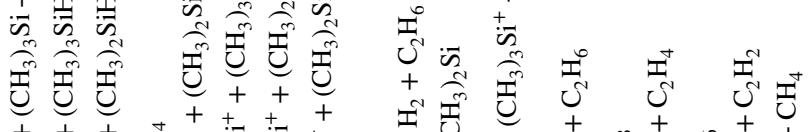

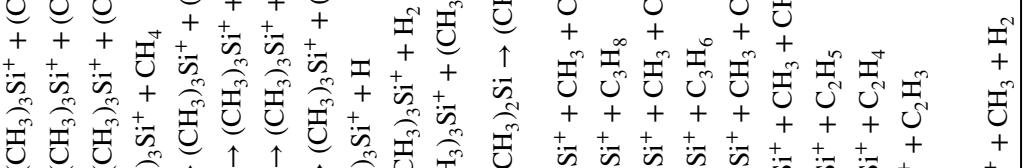

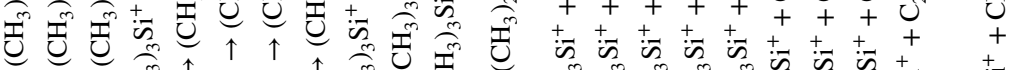

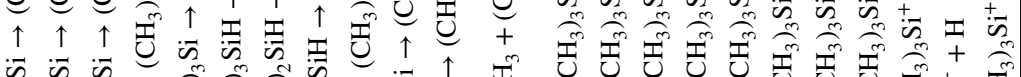

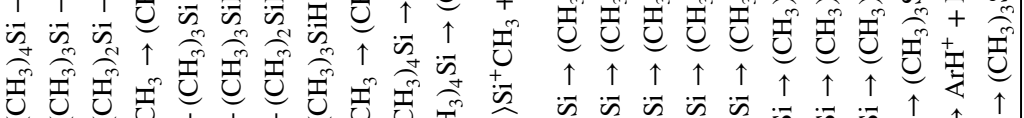

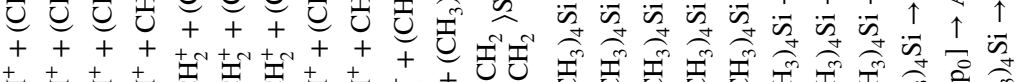

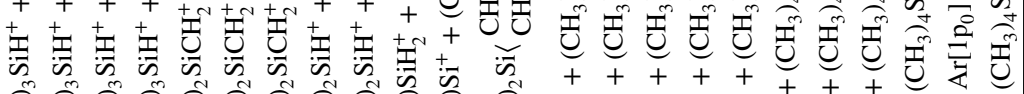
苞焉 


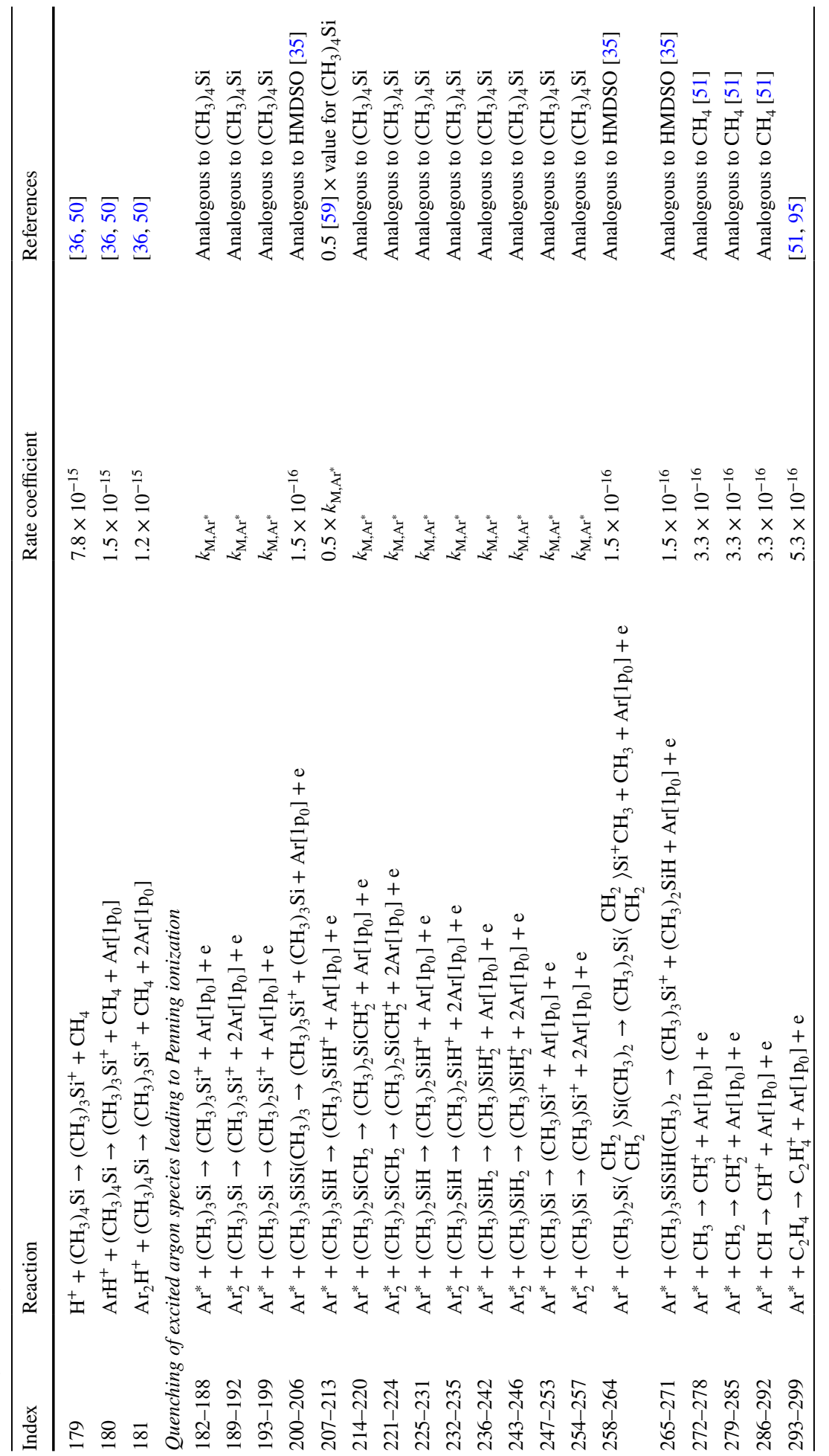




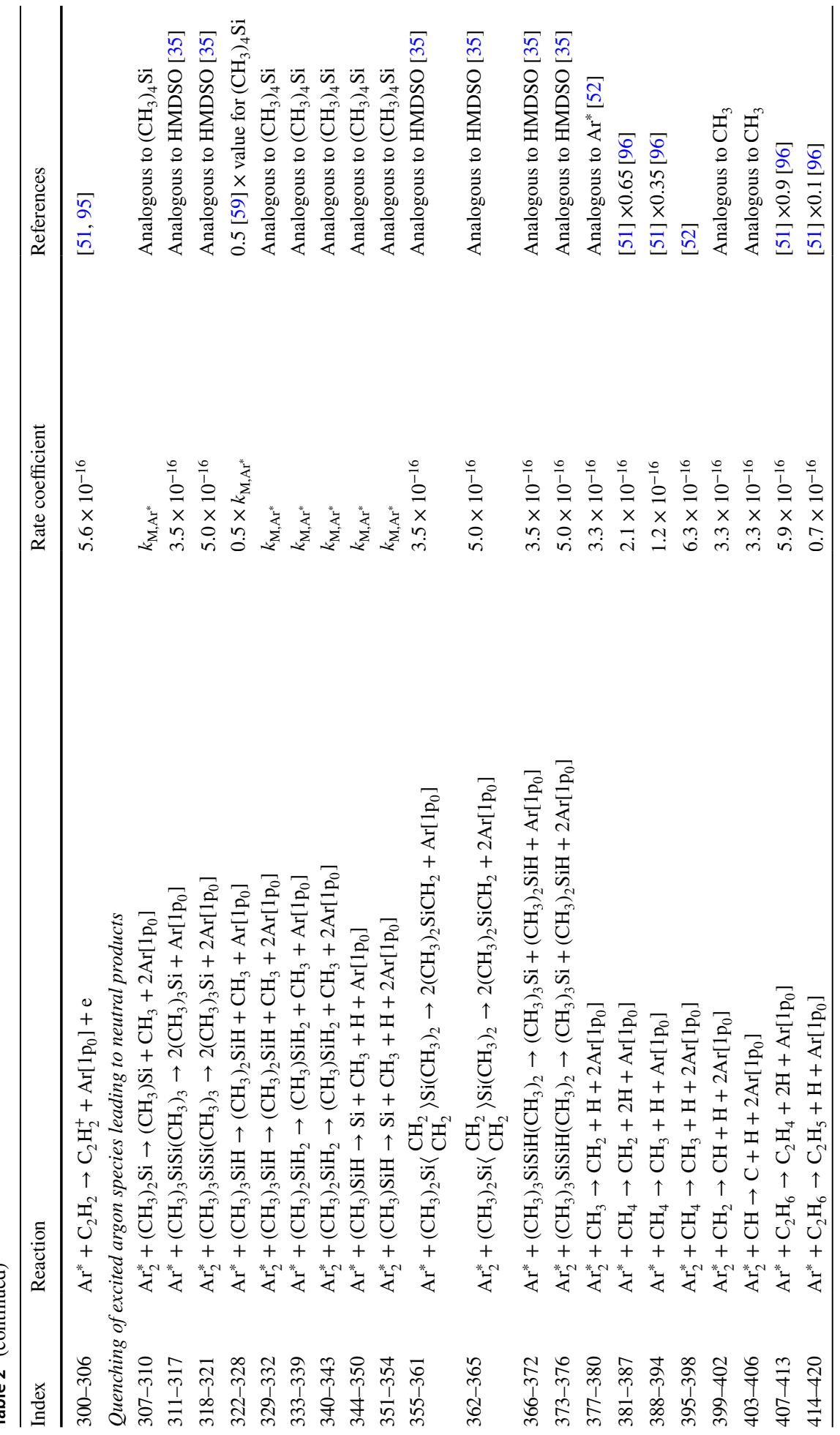




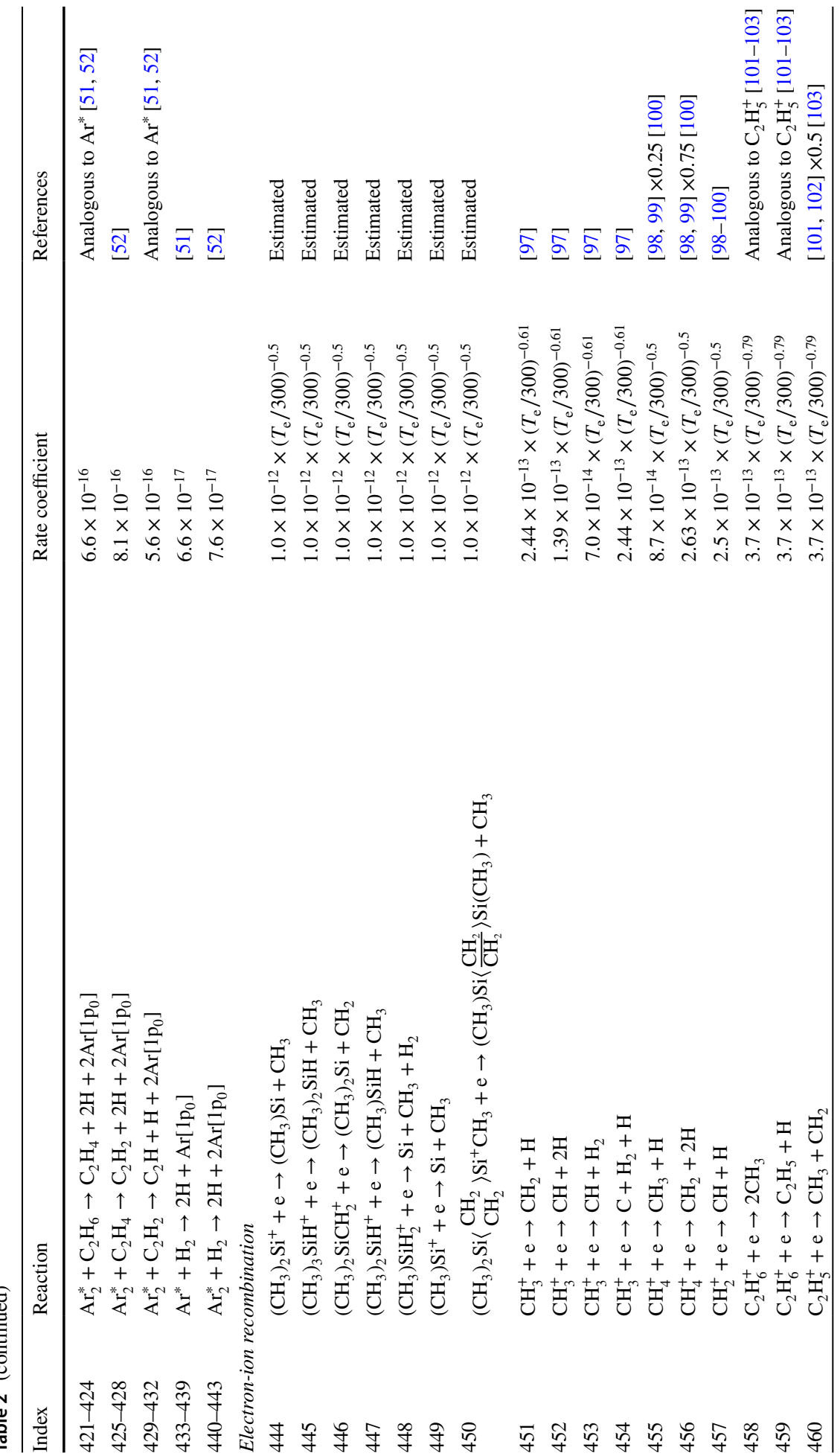




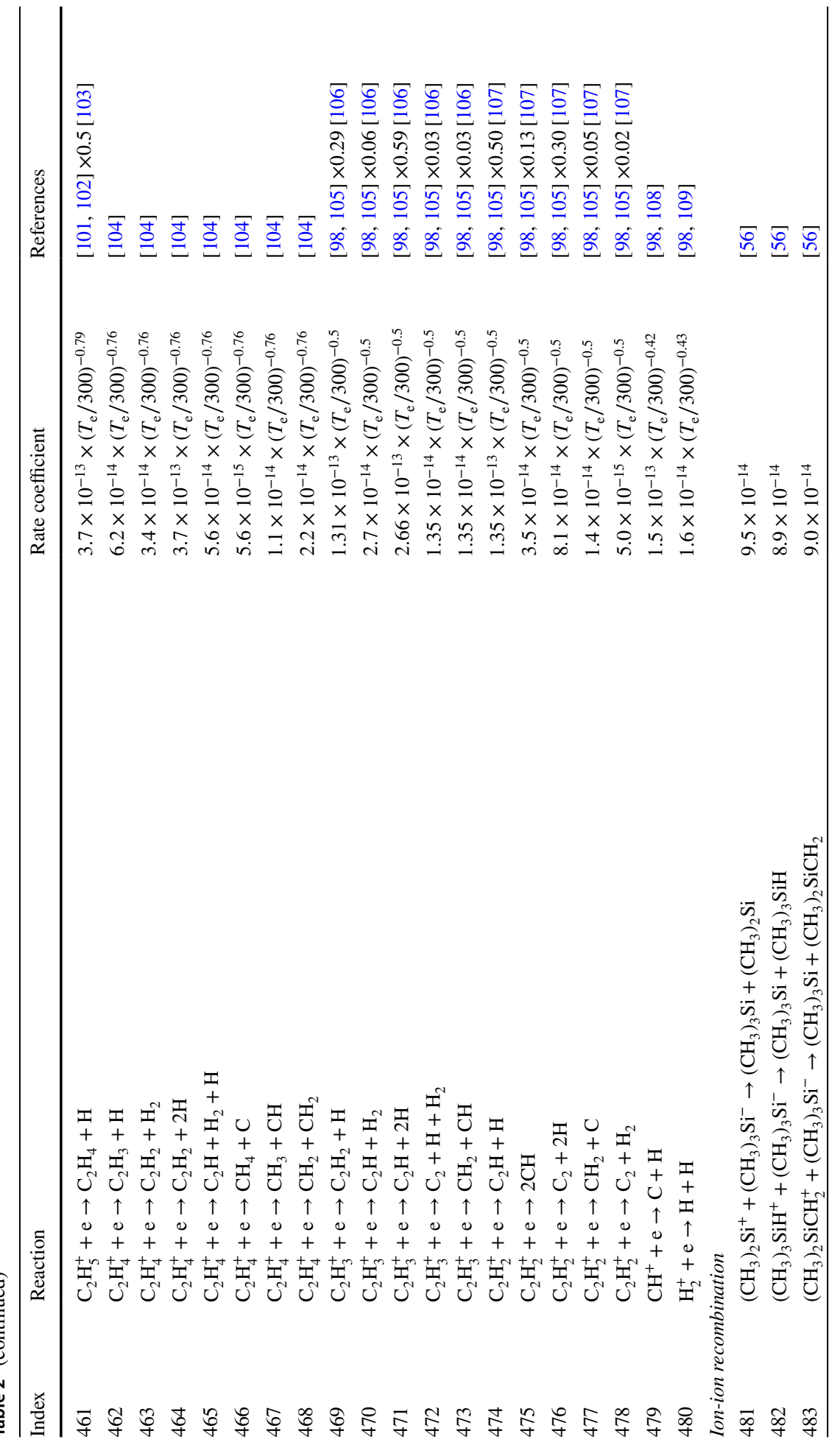




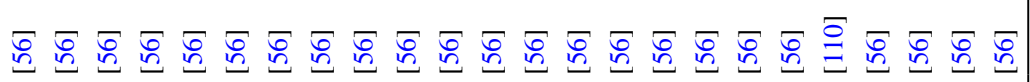

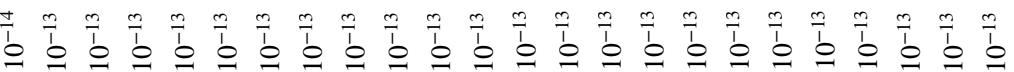

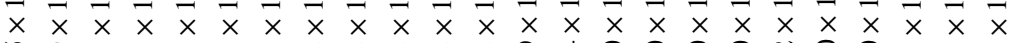

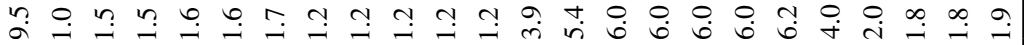

䨌

i

要 $\frac{5}{\sqrt{9}}$

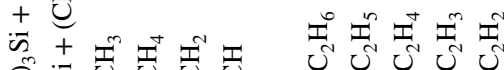

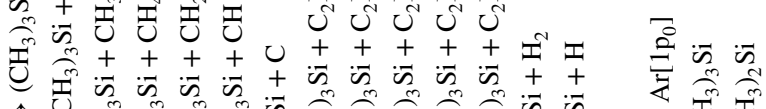

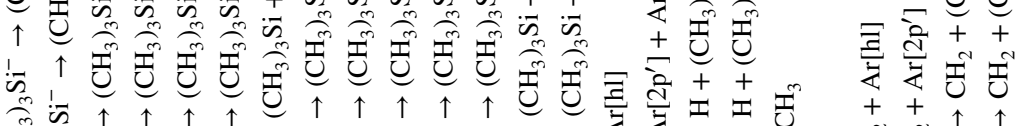

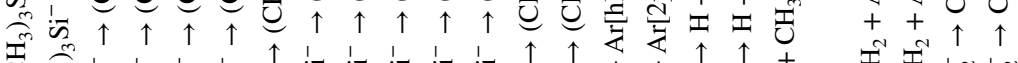

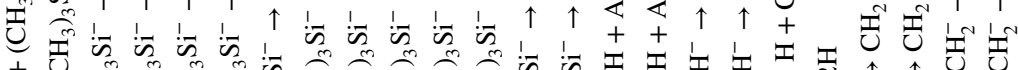
+ 记

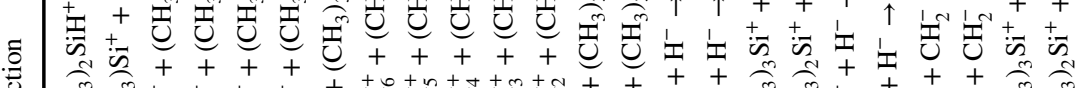

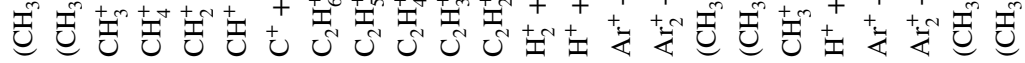

量| 


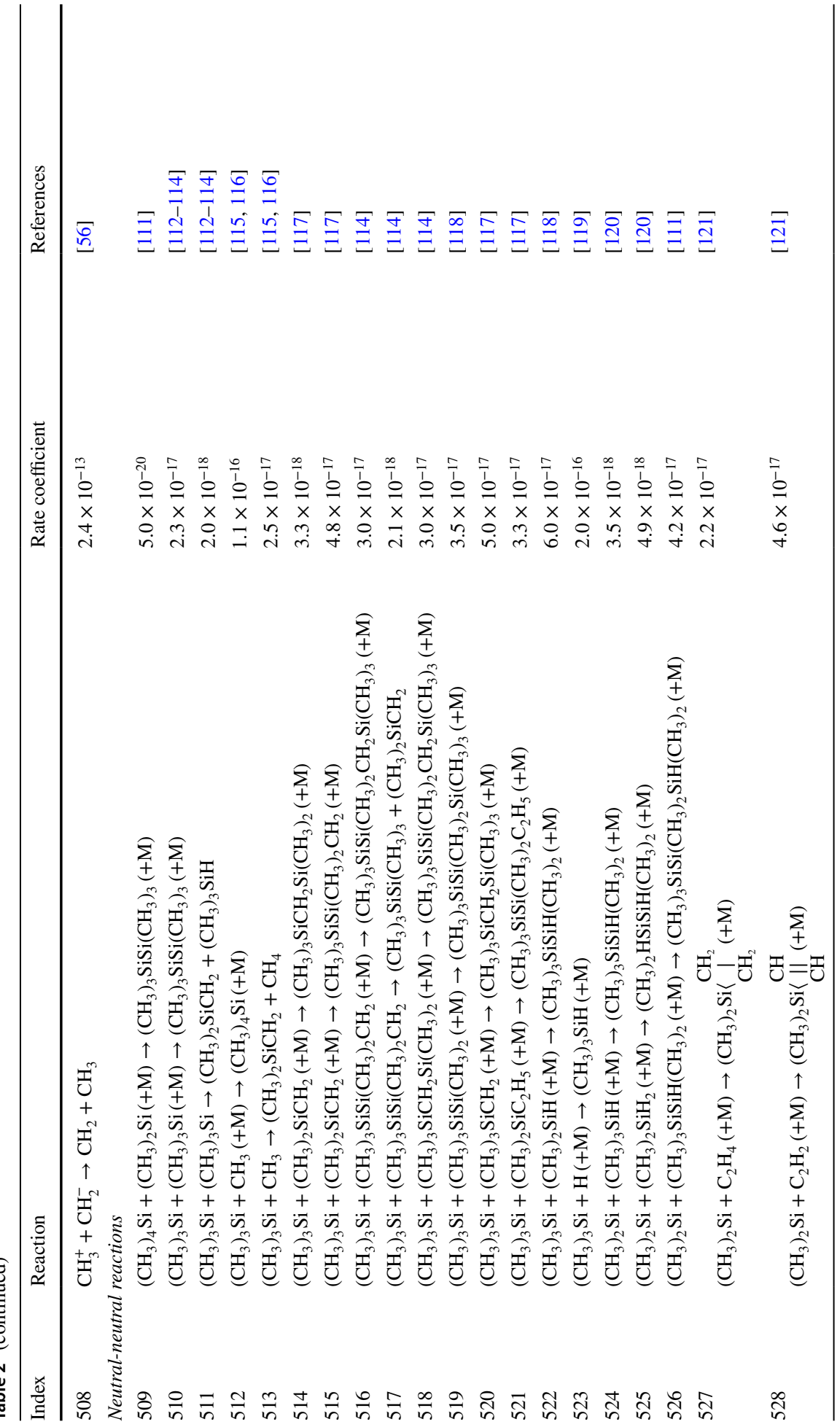




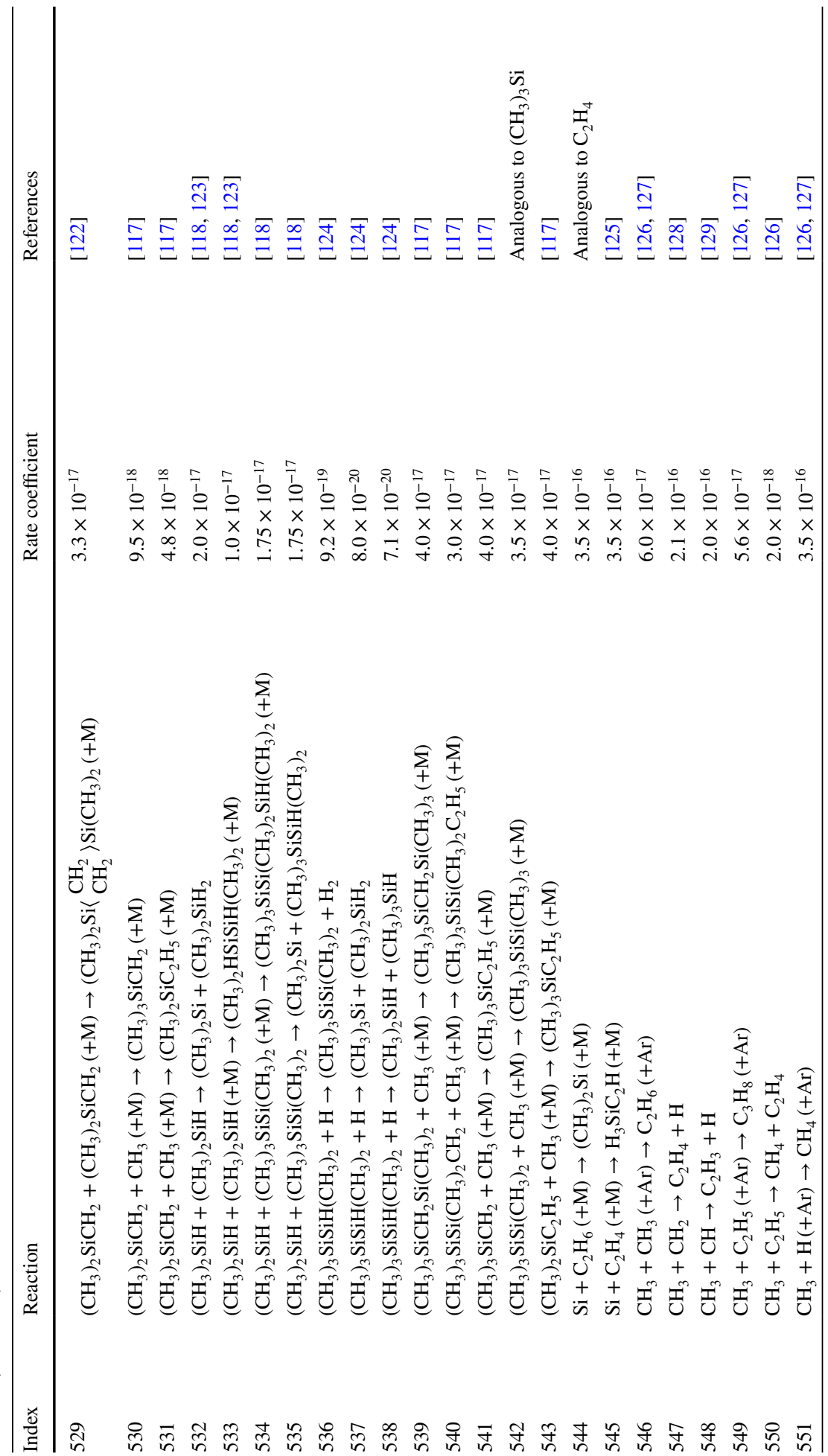



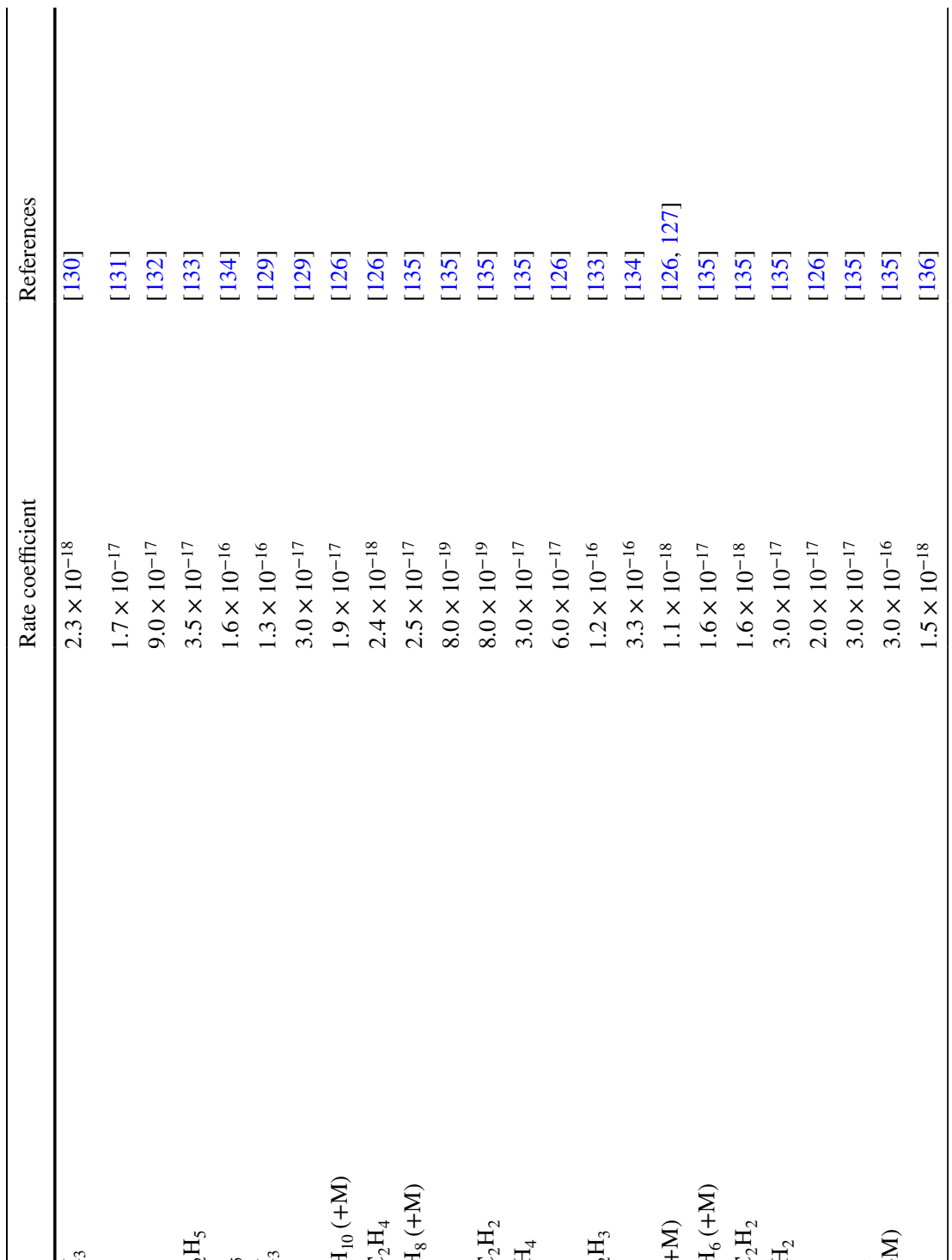

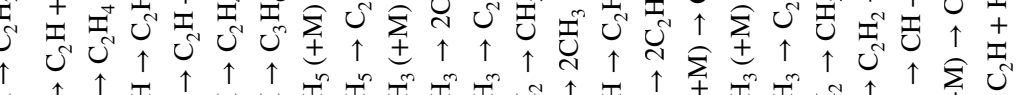

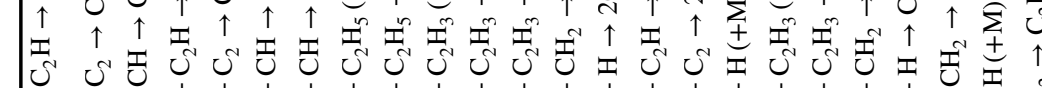
.

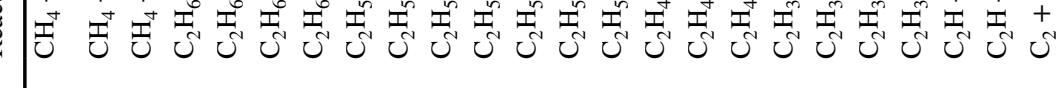

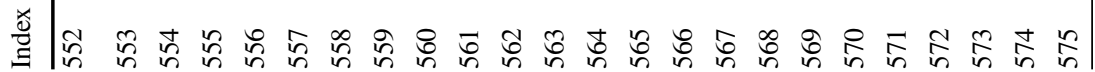




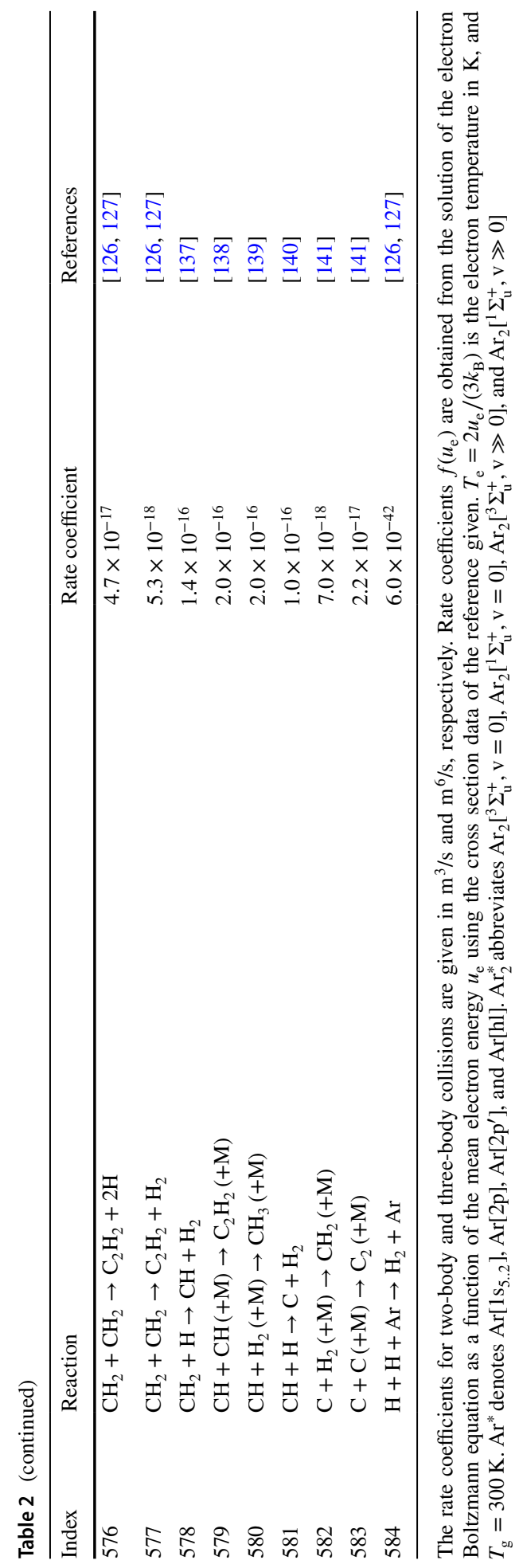




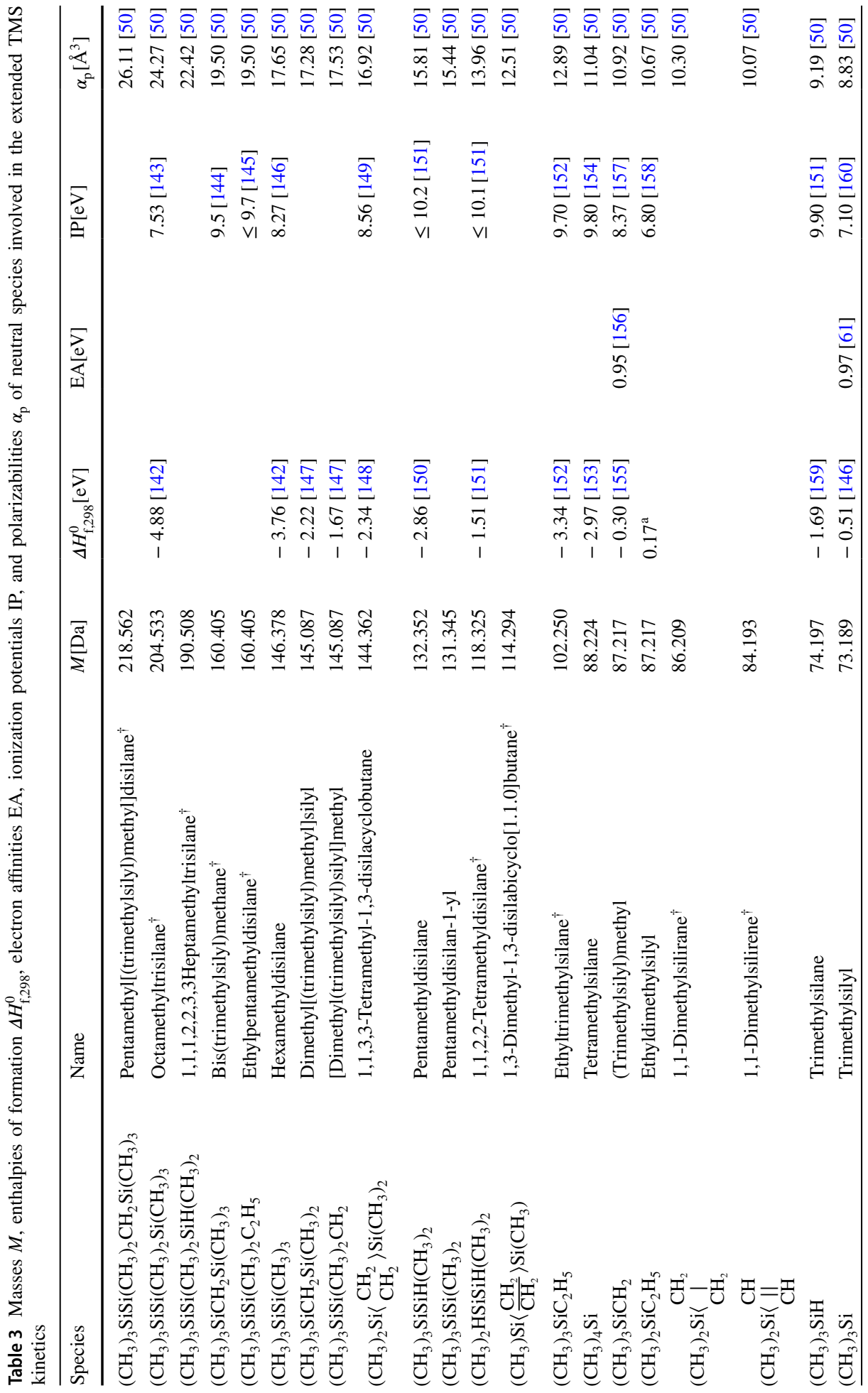




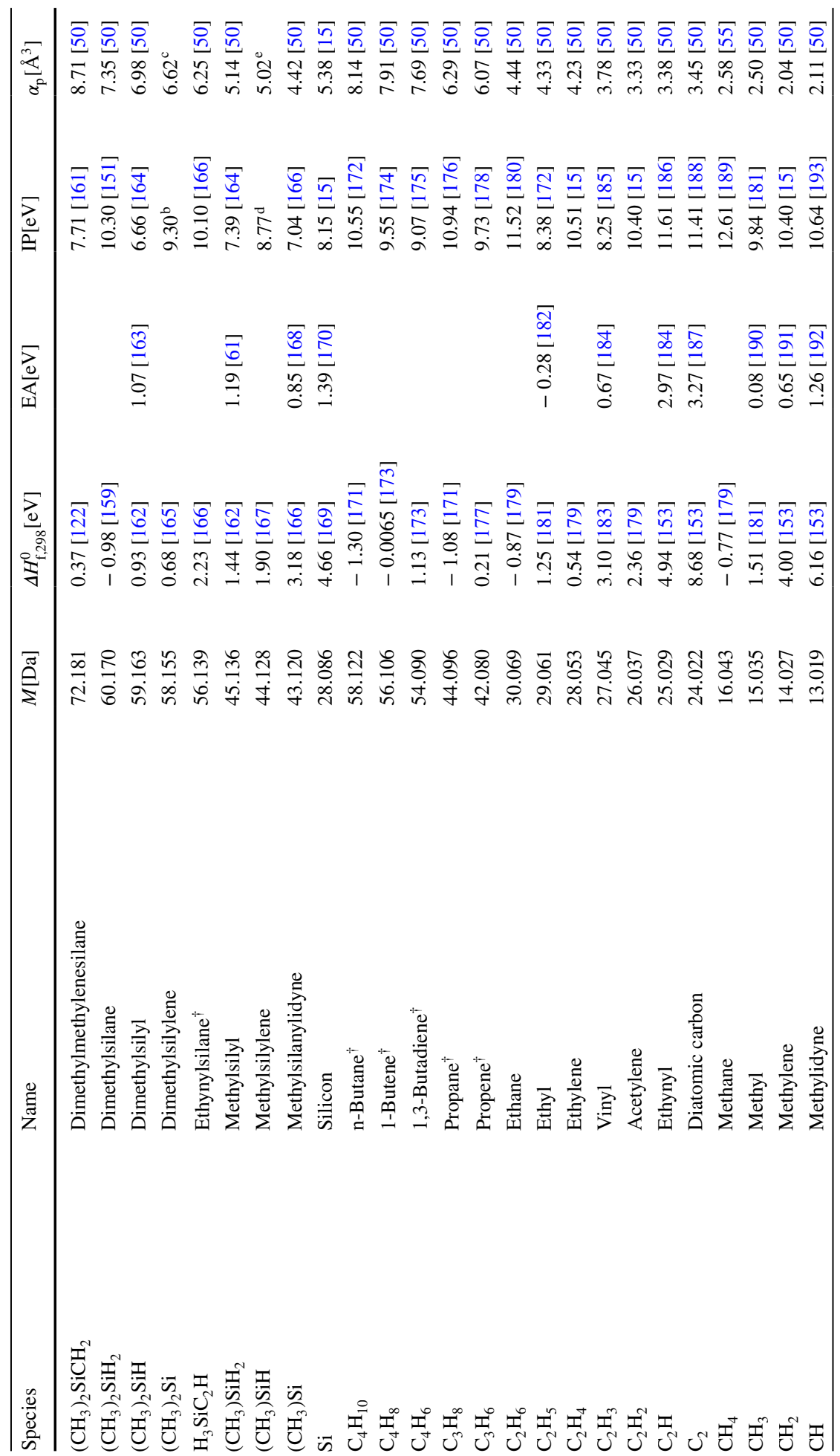




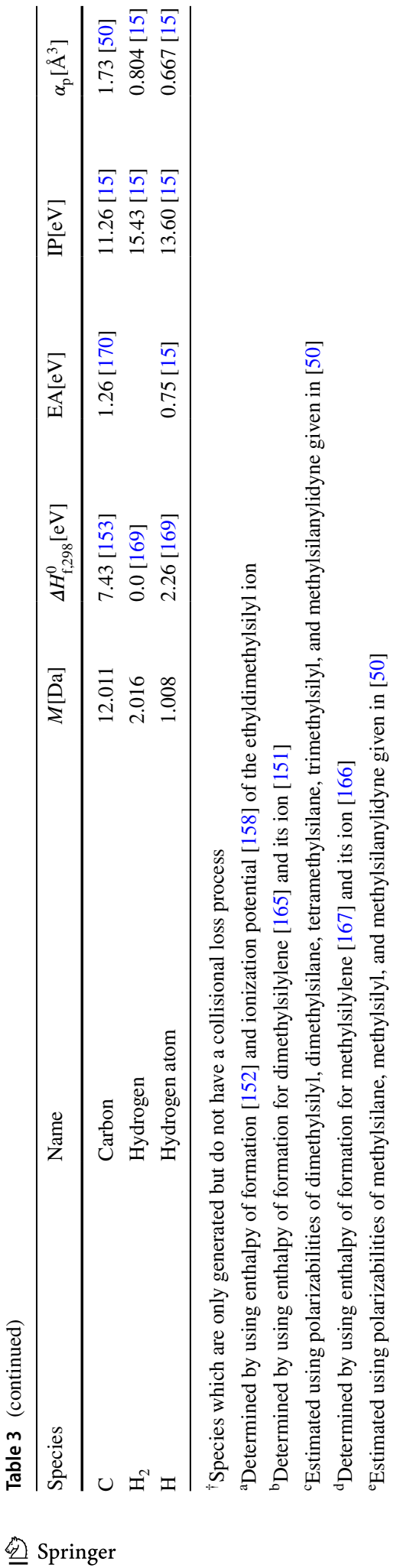


Table 4 Nominal masses $M / Z$ and background gas density times mobilities $N \mu_{\text {io }}$ of ions considered in the extended TMS kinetics

\begin{tabular}{|c|c|c|c|}
\hline & Name & $M / Z$ & $N \mu_{\mathrm{io}}\left[10^{21}(\mathrm{~V} \mathrm{~m} \mathrm{~s})^{-1}\right]$ \\
\hline \multicolumn{4}{|l|}{ Positive ions } \\
\hline$\left(\mathrm{CH}_{3}\right)_{2} \mathrm{Si}\left\langle\underset{\mathrm{CH}_{2}}{\mathrm{CH}_{2}}\right\rangle \mathrm{Si}^{+} \mathrm{CH}_{3}$ & $\begin{array}{l}\text { 1,1,3-trimethyl-1,3-disilacyclobu- } \\
\text { tane-1-yl cation }\end{array}$ & 129 & 5.3 \\
\hline $\mathrm{Ar}_{2} \mathrm{H}^{+}$ & Argon hydride cation & 81 & 5.6 \\
\hline$\left(\mathrm{CH}_{3}\right)_{3} \mathrm{SiH}^{+}$ & Trimethylsilane cation & 74 & 5.7 \\
\hline$\left(\mathrm{CH}_{3}\right)_{3} \mathrm{Si}^{+}$ & Trimethylsilyl cation & 73 & 5.7 \\
\hline$\left(\mathrm{CH}_{3}\right)_{2} \mathrm{SiCH}_{2}^{+}$ & Dimethylmethylenesilane cation & 72 & 5.7 \\
\hline$\left(\mathrm{CH}_{3}\right)_{2} \mathrm{SiH}^{+}$ & Dimethylsilyl cation & 59 & 5.9 \\
\hline$\left(\mathrm{CH}_{3}\right)_{2} \mathrm{Si}^{+}$ & Dimethylsilylene cation & 58 & 6.0 \\
\hline$\left(\mathrm{CH}_{3}\right) \mathrm{SiH}_{2}^{+}$ & Methylsilyl cation & 45 & 6.3 \\
\hline$\left(\mathrm{CH}_{3}\right) \mathrm{Si}^{+}$ & Methylsilanylidyne cation & 43 & 6.4 \\
\hline $\mathrm{ArH}^{+}$ & Argonium & 41 & 6.4 \\
\hline $\mathrm{C}_{2} \mathrm{H}_{6}^{+}$ & Ethane cation & 30 & 7.0 \\
\hline $\mathrm{C}_{2} \mathrm{H}_{5}^{+}$ & Ethyl cation & 29 & 7.1 \\
\hline $\mathrm{C}_{2} \mathrm{H}_{4}^{+}$ & Ethylene cation & 28 & 7.1 \\
\hline $\mathrm{C}_{2} \mathrm{H}_{3}^{+}$ & Vinyl cation & 27 & 7.2 \\
\hline $\mathrm{C}_{2} \mathrm{H}_{2}^{+}$ & Acetylene cation & 26 & 7.3 \\
\hline $\mathrm{CH}_{4}^{+}$ & Methane cation & 16 & 8.6 \\
\hline $\mathrm{CH}_{3}^{+}$ & Methyl cation & 15 & 8.8 \\
\hline $\mathrm{CH}_{2}^{+}$ & Methylene cation & 14 & 9.0 \\
\hline $\mathrm{CH}^{+}$ & Methylidyne cation & 13 & 9.3 \\
\hline $\mathrm{C}^{+}$ & Carbon cation & 12 & 9.5 \\
\hline $\mathrm{H}_{2}^{+}$ & Molecular hydrogen cation & 2 & 20.9 \\
\hline $\mathrm{H}^{+}$ & Hydrogen cation & 1 & 29.2 \\
\hline \multicolumn{4}{|l|}{ Negative ions } \\
\hline$\left(\mathrm{CH}_{3}\right)_{3} \mathrm{Si}^{-}$ & Trimethylsilyl anion & -73 & 5.7 \\
\hline $\mathrm{CH}_{2}^{-}$ & Methylene anion & -14 & 9.0 \\
\hline $\mathrm{H}^{-}$ & Hydrogen anion & -1 & 29.2 \\
\hline
\end{tabular}

Furthermore, transport coefficients of ions and neutrals are required for the modeling studies. The product of ion mobility times background gas density was determined by use of the polarization mobility [64] obtained from the Langevin theory for all ions. The resulting values are summarized in Table 4 . The corresponding diffusion coefficients of the ions were calculated using Einstein's relation [36].

To calculated the diffusion coefficients of the various neutral species in Ar at room temperature, two approaches were applied. The first one is the theory of Chapman and Enskog [194], which requires knowledge about the Lennard-Jones (6-12) potential parameters $\sigma$ and $\varepsilon / k_{\mathrm{B}}$. These parameters are known from the literature for TMS, Si and a number of hydrocarbons as well as atomic and molecular hydrogen and carbon. Furthermore, the empirical relations given in the monograph by Bird et al. [194] were used to determine the Lennard-Jones parameters from the liquid data of the molar volume and boiling point, which are also available in the literature for several stable organosilicon molecules. The 
resulting values of diffusion coefficient times background gas density were applied in the numerical modeling studies. They are listed in Table 5.

The second approach to calculate binary-gas phase diffusion coefficients is the diffusion-volume method introduced by Fuller, Schettler and Giddings [195]. This method was used for all other neutral species, where the diffusion volumes for $\mathrm{Ar}, \mathrm{H}$, and $\mathrm{C}$ were taken from [196] and that for $\mathrm{Si}$ was estimated as $27.0 \mathrm{~cm}^{3}$. This value was found to yield good agreement with results of the Chapman-Enskog theory for most of the silicon- and hydrogen-containing species listed in [44]. The resulting values of diffusion coefficient times background gas density are compiled in Table 5. Notice that the agreement between the values obtained by both the methods is also generally very well for all silicon-containing species included in that table.

\section{Results and Discussion}

Model calculations were carried out for Ar-TMS mixtures at atmospheric pressure and a gas temperature of $300 \mathrm{~K}$, with a TMS fraction $x$ between 0 and $200 \mathrm{ppm}$ and an argon amount of $(1-x)$, in accordance with related experimental studies. The modeling studies comprise an analysis of the ignition voltage of DBDs in Ar-TMS mixtures as well as a characterization of the temporal discharge behavior of such DBDs operating under conditions typical of film-deposition experiments. Therefore, the coupled set of partial differential equations illustrated in Fig. 2 was solved numerically by means of a finite difference method according to Becker et al. [34, 41]. In particular, an adaptive time stepping and a non-equidistant spatial grid using generally 500 intervals with logarithmically refined mesh towards the boundaries were employed for the model calculations reported in "Analysis of the Ignition Voltage" section.

\section{Analysis of the Ignition Voltage}

Numerical studies of the ignition voltage $U_{\mathrm{i}}$ were performed for the experimental setup shown in Fig. 1a. They were supplemented by an experimental determination of $U_{\mathrm{i}}$. For this an HV generator (G2000, Redline Technologies, Baesweiler, Germany) was used to power the discharge with the sinusoidal voltage (1) at $f=86.2 \mathrm{kHz}$, which corresponds to a period duration of $T=11.6 \mu \mathrm{s}$. The electrical circuit used for measurements of the applied voltage $U_{\mathrm{a}}(t)$ and $U_{\mathrm{i}}$ as well as of the current or transferred charge (see "Temporal Behavior of DBDs in Ar-TMS Mixtures" section) is illustrated in Fig. 3. $U_{\mathrm{a}}(t)$ was measured by means of an HV probe (PHV 4002-3, dataTec, Reutlingen, Germany) connected to an oscilloscope (MDO3052, Tektronix, Beaverton, OR, USA). In order to determine $U_{\mathrm{i}}$, the amplitude $U_{\mathrm{a}, 0}$ of the applied voltage was increased step by step for a specific Ar-TMS mixture until the discharge was ignited and covered the entire electrode area, i.e., $U_{\mathrm{i}}=U_{\mathrm{a}, 0}$. The purity of argon gas (obtained from Linde AG, Germany) was $\geq 99.9999 \%$ and that of TMS (from Sigma-Aldrich Chemie GmbH, Germany) was $\geq 99 \%$. The gas flow rate $F$ was 6 slm in the experiments.

Figure 4 shows modeling results of $U_{\mathrm{i}}$ obtained for different sets of rate coefficient $k_{\mathrm{M}, \mathrm{Ar}^{*}}$ and Penning ionization fraction $\alpha_{\mathrm{Pl}}$ for reactions (2) and (3) of TMS with excited argon atoms in comparison with experimental values. The measured ignition voltage decreases monotonically from about $3.0 \mathrm{kV}$ in pure argon to $1.25 \mathrm{kV}$ at $x=200 \mathrm{ppm}$, where the initially rapid drop becomes smaller above about $x=50 \mathrm{ppm}$. A quite similar 
Table 5 Lennard-Jones parameters, and background gas density times binary diffusion coefficients $N D$ in argon at $300 \mathrm{~K}$ obtained by Chapman-Enskog theory [194] (index CE) and the method of Fuller, Schettler and Giddings $[195,196]$ (index FSG) using a diffusion volume for Si of $27.0 \mathrm{~cm}^{3}$

\begin{tabular}{|c|c|c|c|c|}
\hline Species & $\sigma[\AA ̊]$ & $\varepsilon / k_{\mathrm{B}}[\mathrm{K}]$ & $N D_{\mathrm{CE}}\left[\mathrm{m}^{-1} \mathrm{~s}^{-1}\right]$ & $N D_{\mathrm{FSG}}\left[\mathrm{m}^{-1} \mathrm{~s}^{-1}\right]$ \\
\hline$\left(\mathrm{CH}_{3}\right)_{3} \mathrm{SiSi}\left(\mathrm{CH}_{3}\right)_{2} \mathrm{CH}_{2} \mathrm{Si}\left(\mathrm{CH}_{3}\right)_{3}$ & & & & $1.1 \times 10^{20}$ \\
\hline$\left(\mathrm{CH}_{3}\right)_{3} \mathrm{SiSi}\left(\mathrm{CH}_{3}\right)_{2} \mathrm{Si}\left(\mathrm{CH}_{3}\right)_{3}$ & $7.196^{\dagger}[198]$ & $508.2^{\dagger}[198]$ & $1.1 \times 10^{20}$ & $1.1 \times 10^{20}$ \\
\hline$\left(\mathrm{CH}_{3}\right)_{3} \mathrm{SiSi}\left(\mathrm{CH}_{3}\right)_{2} \mathrm{SiH}\left(\mathrm{CH}_{3}\right)_{2}$ & & & & $1.2 \times 10^{20}$ \\
\hline$\left(\mathrm{CH}_{3}\right)_{3} \mathrm{SiCH}_{2} \mathrm{Si}\left(\mathrm{CH}_{3}\right)_{3}$ & $6.692^{\dagger}[198]$ & $468.3^{\dagger}[198]$ & $1.3 \times 10^{20}$ & $1.3 \times 10^{20}$ \\
\hline$\left(\mathrm{CH}_{3}\right)_{3} \mathrm{SiSi}\left(\mathrm{CH}_{3}\right)_{2} \mathrm{C}_{2} \mathrm{H}_{5}$ & $6.692^{\dagger}[198]$ & $472.4^{\dagger}[198]$ & $1.3 \times 10^{20}$ & $1.3 \times 10^{20}$ \\
\hline$\left(\mathrm{CH}_{3}\right)_{3} \mathrm{SiSi}\left(\mathrm{CH}_{3}\right)_{3}$ & $6.548^{\dagger}[15]$ & $444.7^{\dagger}[15]$ & $1.3 \times 10^{20}$ & $1.4 \times 10^{20}$ \\
\hline$\left(\mathrm{CH}_{3}\right)_{3} \mathrm{SiCH}_{2} \mathrm{Si}\left(\mathrm{CH}_{3}\right)_{2}$ & & & & $1.4 \times 10^{20}$ \\
\hline$\left(\mathrm{CH}_{3}\right)_{3} \mathrm{SiSi}\left(\mathrm{CH}_{3}\right)_{2} \mathrm{CH}_{2}$ & & & & $1.4 \times 10^{20}$ \\
\hline$\left(\mathrm{CH}_{3}\right)_{2} \mathrm{Si}\left\langle\stackrel{\mathrm{CH}_{2}}{\mathrm{CH}_{2}}\right\rangle \mathrm{Si}\left(\mathrm{CH}_{3}\right)_{2}$ & $6.306^{\dagger}[198]$ & $452.7^{\dagger}[198]$ & $1.4 \times 10^{20}$ & $1.4 \times 10^{20}$ \\
\hline$\left(\mathrm{CH}_{3}\right)_{3} \mathrm{SiSiH}\left(\mathrm{CH}_{3}\right)_{2}$ & $6.340^{\dagger}[198]$ & $428.7^{\dagger}[198]$ & $1.4 \times 10^{20}$ & $1.5 \times 10^{20}$ \\
\hline$\left(\mathrm{CH}_{3}\right)_{3} \mathrm{SiSi}\left(\mathrm{CH}_{3}\right)_{2}$ & & & & $1.5 \times 10^{20}$ \\
\hline$\left(\mathrm{CH}_{3}\right)_{2} \mathrm{HSiSiH}\left(\mathrm{CH}_{3}\right)_{2}$ & $6.127^{\dagger}[198]$ & $413.6^{\dagger}[198]$ & $1.5 \times 10^{20}$ & $1.6 \times 10^{20}$ \\
\hline$\left(\mathrm{CH}_{3}\right) \mathrm{Si}\left\langle\frac{\mathrm{CH}_{2}}{\mathrm{CH}_{2}}\right\rangle \mathrm{Si}\left(\mathrm{CH}_{3}\right)$ & & & & $1.6 \times 10^{20}$ \\
\hline$\left(\mathrm{CH}_{3}\right)_{3} \mathrm{SiC}_{2} \mathrm{H}_{5}$ & $5.889^{\dagger}[198]$ & $381.6^{\dagger}[198]$ & $1.6 \times 10^{20}$ & $1.7 \times 10^{20}$ \\
\hline$\left(\mathrm{CH}_{3}\right)_{4} \mathrm{Si}$ & 8.137 [199] & 223.1 [199] & $1.2 \times 10^{20}$ & $1.8 \times 10^{20}$ \\
\hline$\left(\mathrm{CH}_{3}\right)_{3} \mathrm{SiCH}_{2}$ & & & & $1.8 \times 10^{20}$ \\
\hline$\left(\mathrm{CH}_{3}\right)_{2} \mathrm{SiC}_{2} \mathrm{H}_{5}$ & & & & $1.8 \times 10^{20}$ \\
\hline$\left(\mathrm{CH}_{3}\right)_{2} \mathrm{Si}<\underset{\mathrm{CH}_{2}}{\mathrm{CH}_{2}}$ & & & & $1.9 \times 10^{20}$ \\
\hline$\left(\mathrm{CH}_{3}\right)_{2} \mathrm{Si}<\underset{\mathrm{CH}}{\mathrm{CH}}$ & & & & $1.9 \times 10^{20}$ \\
\hline$\left(\mathrm{CH}_{3}\right)_{3} \mathrm{SiH}$ & $5.447^{\dagger}[200]$ & $321.8^{\dagger}[200]$ & $2.0 \times 10^{20}$ & $2.0 \times 10^{20}$ \\
\hline$\left(\mathrm{CH}_{3}\right)_{3} \mathrm{Si}$ & & & & $2.1 \times 10^{20}$ \\
\hline$\left(\mathrm{CH}_{3}\right)_{2} \mathrm{SiCH}_{2}$ & & & & $2.1 \times 10^{20}$ \\
\hline$\left(\mathrm{CH}_{3}\right)_{2} \mathrm{SiH}_{2}$ & $5.563^{\dagger}[200]$ & $236.0^{\dagger}[200]$ & $2.1 \times 10^{20}$ & $2.3 \times 10^{20}$ \\
\hline$\left(\mathrm{CH}_{3}\right)_{2} \mathrm{SiH}$ & & & & $2.4 \times 10^{20}$ \\
\hline$\left(\mathrm{CH}_{3}\right)_{2} \mathrm{Si}$ & & & & $2.4 \times 10^{20}$ \\
\hline $\mathrm{H}_{3} \mathrm{SiC}_{2} \mathrm{H}$ & & & & $2.5 \times 10^{20}$ \\
\hline$\left(\mathrm{CH}_{3}\right) \mathrm{SiH}_{2}$ & & & & $2.9 \times 10^{20}$ \\
\hline$\left(\mathrm{CH}_{3}\right) \mathrm{SiH}$ & & & & $2.9 \times 10^{20}$ \\
\hline$\left(\mathrm{CH}_{3}\right) \mathrm{Si}$ & & & & $3.0 \times 10^{20}$ \\
\hline $\mathrm{Si}$ & $2.005[201]$ & 18640 [201] & $3.0 \times 10^{20}$ & $4.3 \times 10^{20}$ \\
\hline $\mathrm{C}_{4} \mathrm{H}_{10}$ & 4.687 [202] & 531.4 [202] & $2.2 \times 10^{20}$ & $2.2 \times 10^{20}$ \\
\hline $\mathrm{C}_{4} \mathrm{H}_{8}$ & $4.994^{\dagger}[198]$ & $306.9^{\dagger}[198]$ & $2.3 \times 10^{20}$ & $2.3 \times 10^{20}$ \\
\hline $\mathrm{C}_{4} \mathrm{H}_{6}$ & $4.903^{\dagger}[198]$ & $309.1^{\dagger}[198]$ & $2.4 \times 10^{20}$ & $2.4 \times 10^{20}$ \\
\hline $\mathrm{C}_{3} \mathrm{H}_{8}$ & $4.724^{\dagger}[203]$ & $265.7^{\dagger}[203]$ & $2.7 \times 10^{20}$ & $2.7 \times 10^{20}$ \\
\hline $\mathrm{C}_{3} \mathrm{H}_{6}$ & $4.579^{\dagger}[203]$ & $259.3^{\dagger}[203]$ & $2.8 \times 10^{20}$ & $2.8 \times 10^{20}$ \\
\hline $\mathrm{C}_{2} \mathrm{H}_{6}$ & 4.443 [202] & 215.7 [202] & $3.3 \times 10^{20}$ & $3.4 \times 10^{20}$ \\
\hline $\mathrm{C}_{2} \mathrm{H}_{5}$ & & & & $3.5 \times 10^{20}$ \\
\hline
\end{tabular}


Table 5 (continued)

\begin{tabular}{lllll}
\hline Species & $\sigma[\AA]$ & $\varepsilon / k_{\mathrm{B}}[\mathrm{K}]$ & $N D_{\mathrm{CE}}\left[\mathrm{m}^{-1} \mathrm{~s}^{-1}\right]$ & $N D_{\mathrm{FSG}}\left[\mathrm{m}^{-1} \mathrm{~s}^{-1}\right]$ \\
\hline $\mathrm{C}_{2} \mathrm{H}_{4}$ & $4.163[202]$ & $224.7[202]$ & $3.6 \times 10^{20}$ & $3.6 \times 10^{20}$ \\
$\mathrm{C}_{2} \mathrm{H}_{3}$ & & & & $3.8 \times 10^{20}$ \\
$\mathrm{C}_{2} \mathrm{H}_{2}$ & $4.033[202]$ & $231.8[202]$ & $3.8 \times 10^{20}$ & $3.9 \times 10^{20}$ \\
$\mathrm{C}_{2} \mathrm{H}$ & & & & $4.0 \times 10^{20}$ \\
$\mathrm{C}_{2}$ & $3.913[202]$ & $78.8[202]$ & $4.8 \times 10^{20}$ & $4.2 \times 10^{20}$ \\
$\mathrm{CH}_{4}$ & $3.882[197]$ & $136.5[197]$ & $5.1 \times 10^{20}$ & $5.2 \times 10^{20}$ \\
$\mathrm{CH}_{3}$ & $3.905[204]$ & $88.1[204]$ & $5.6 \times 10^{20}$ & $5.6 \times 10^{20}$ \\
$\mathrm{CH}_{2}$ & $3.905[204]$ & $59.4[204]$ & $6.0 \times 10^{20}$ & $5.9 \times 10^{20}$ \\
$\mathrm{CH}^{3}$ & $3.370[202]$ & $68.6[202]$ & $7.0 \times 10^{20}$ & $6.3 \times 10^{20}$ \\
$\mathrm{C}$ & $3.385[202]$ & $30.6[202]$ & $7.9 \times 10^{20}$ & $6.8 \times 10^{20}$ \\
$\mathrm{H}_{2}$ & $2.827[202]$ & $59.7[202]$ & $1.9 \times 10^{21}$ & $2.2 \times 10^{21}$ \\
$\mathrm{H}$ & $2.708[202]$ & $37.0[202]$ & $2.9 \times 10^{21}$ & $3.6 \times 10^{21}$ \\
\hline
\end{tabular}

The Lennard-Jones parameters for argon are $\sigma=3.418 \AA$ and $\varepsilon / k_{\mathrm{B}}=124.0 \mathrm{~K}$ [197]. ${ }^{\dagger}$ : estimated from empirical relations given on page 22 of [194] using molar volume and boiling point given in the reference

Fig. 3 Electrical circuit used for voltage and current measurements

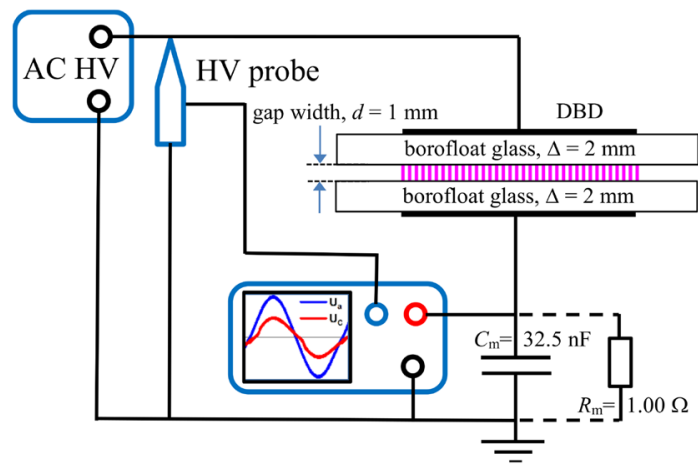

Fig. 4 Ignition voltages obtained by measurements and by modeling using different parameter sets of $k_{\mathrm{M}, \mathrm{Ar}^{*}}$ and $\alpha_{\mathrm{Pl}}$ in dependence on the TMS fraction $x$

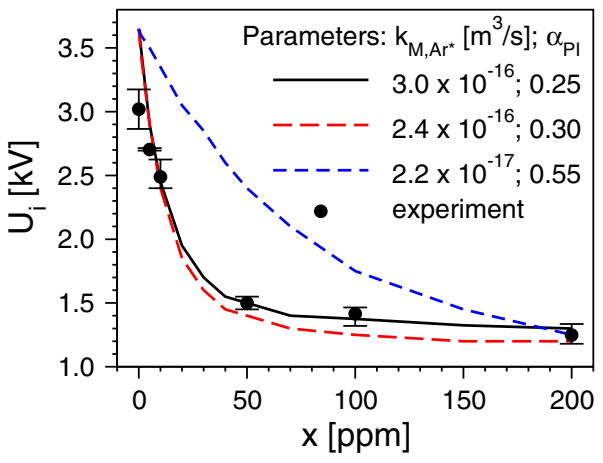


behavior of the ignition voltage for mixtures of Ar and HMDSO was reported for the same DBD configuration in [35]. There, the monotonic decrease resulted in $U_{\mathrm{i}}=1.0 \mathrm{kV}$ at $x=200 \mathrm{ppm}$ and it could be well described by modeling results, when employing the measured rate coefficient of $5.0 \times 10^{-16} \mathrm{~m}^{3} / \mathrm{s}$ [58] for Ar*-HMDSO reactions and a corresponding Penning ionization fraction of $30 \%$ in the reaction kinetics model.

The decrease of $U_{\mathrm{i}}$ with increasing TMS admixture obtained from the experiments is also found by the modeling studies for all sets of $k_{\mathrm{M}, \mathrm{Ar}}$ and $\alpha_{\mathrm{Pl}}$, which assume a certain amount of Penning ionization processes. In particular, best agreement between measured and calculated results is obtained, when $25 \%$ of the reactions of TMS with $\mathrm{Ar}^{*}$ are supposed to lead to the generation of electrons due to Penning ionization at a total rate coefficient $k_{\mathrm{M}, \mathrm{Ar}^{*}}=3.0 \times 10^{-16} \mathrm{~m}^{3} / \mathrm{s}$. The assumption of $\alpha_{\mathrm{Pl}}=0.3$ and $k_{\mathrm{M}, \mathrm{Ar}^{*}}=2.4 \times 10^{-16} \mathrm{~m}^{3} / \mathrm{s}$ in the model calculations also leads to quite good agreement with the measured $U_{\mathrm{i}}$, but the variation with $x$ is not reproduced similarly well. Both these rate coefficients are more than a magnitude larger than that determined experimentally by Jauberteau et al. [57] in the afterglow of a microwave discharge by means of absorption spectroscopy measurements on $\operatorname{Ar}\left[1 \mathrm{~s}_{5}\right]$. The measured total rate coefficient in that paper ranged from $6.0 \times 10^{-18}$ to $2.2 \times 10^{-17} \mathrm{~m}^{3} / \mathrm{s}$. When using the latter value in the model calculations, a Penning ionization fraction for Ar*-TMS reactions of $55 \%$ has to be applied to achieve agreement with the measured ignition voltage at $x=200 \mathrm{ppm}$. However, the decreasing behavior of the measured $U_{\mathrm{i}}$ with increasing $x$ cannot be reproduced that way. Finally, it should be noted that the modeling results obtained by use of the reduced reaction kinetics scheme (Table 1) are identical to those obtained when employing the extended plasma-chemistry model (Tables 1 and 2).

In order to analyze the ionization budget at the ignition voltage for different TMS fractions $x$ in more detail, the space- and period-averaged ionization rates of the different electron production processes were determined from the modeling results using the recommended total rate coefficient $k_{\mathrm{M}, \mathrm{Ar}^{*}}=3.0 \times 10^{-16} \mathrm{~m}^{3} / \mathrm{s}$ and Penning ionization fraction $\alpha_{\mathrm{Pl}}=0.25$. Figure 5 illustrates the corresponding relative contributions of different reaction channels to the total electron production in dependence on $x$. In pure argon, electrons are produced to about $60 \%$ due to electron impact ionization of argon atoms in their ground state and to about $40 \%$ due to chemo-ionization processes in collisions of two excited argon atoms. The contributions of electron impact ionization of excited argon atoms and molecules, respectively, to the total electron production are less than $1 \%$ in pure argon and much smaller when adding TMS. Therefore, they are not displayed in the figure.

Fig. 5 Impact of the TMS fraction $x$ on the electron production channels for applied voltage amplitudes $U_{\mathrm{i}}(x)$

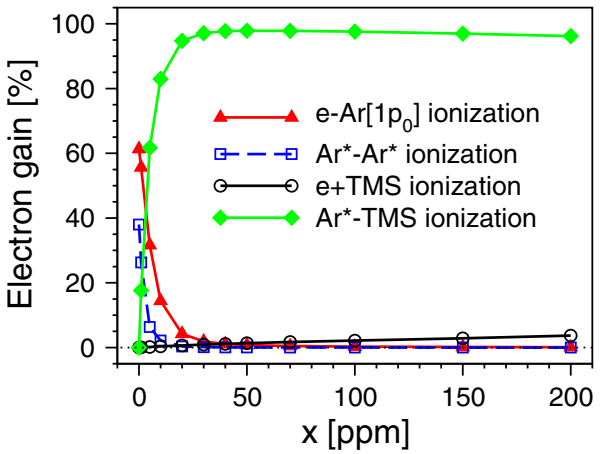


When adding small amounts of TMS to argon, the situation changes drastically. Since the ionization energy of TMS $(9.80 \pm 0.03 \mathrm{eV})$ and the appearance energy of the trimethylsilyl cation $(10.03 \pm 0.04 \mathrm{eV})$ [154] are smaller than the threshold energies for the excitation of argon atoms $(\geq 11.55 \mathrm{eV})[34,205]$, the admixture of TMS is accompanied in particular by the electron production due to Penning ionization according to (2), i.e. reactions 10-16 in Table 1. This collision process becomes the predominant contribution to the electron production already for $x \geq 5 \mathrm{ppm}$. Here, more than $99.9 \%$ of these electrons are produced by reactions of metastable $\left(1 \mathrm{~s}_{5}\right.$ and $\left.1 \mathrm{~s}_{3}\right)$ and resonance $\left(1 \mathrm{~s}_{4}\right.$ and $\left.1 \mathrm{~s}_{2}\right)$ atoms. At the same time, the contribution of the electron- $\operatorname{Ar}\left[1 \mathrm{p}_{0}\right]$ ionization and of the chemo-ionization due to $\mathrm{Ar}^{*}-\mathrm{Ar}^{*}$ collisions decreases and becomes less than $1 \%$ for $x>40 \mathrm{ppm}$ and $x>10 \mathrm{ppm}$, respectively. The contribution of electron impact ionization of TMS increases monotonically with rising TMS fraction, but it contributes to the total electron production only to about $4 \%$ for $x=200 \mathrm{ppm}$. Furthermore, detachment processes of the negative trimethylsilyl ion $\left(\mathrm{CH}_{3}\right)_{3} \mathrm{Si}^{-}$due to collisions with electrons and excited argon species (reactions 6 and 29-39 in Table 1) are found to be insignificant. Moreover, contributions of further species involved in the extended reaction kinetics scheme related to TMS (cf. Table 2) are also negligible because their particle number densities are too small during the ignition phase.

\section{Temporal Behavior of DBDs in Ar-TMS Mixtures}

The analysis of the temporal behavior of DBDs operating under conditions typical of deposition experiments was carried out for Ar-TMS mixtures with an initial TMS fraction $x$ up to $200 \mathrm{ppm}$. Model calculations were done for an applied voltage amplitude $U_{\mathrm{a}, 0}=4 \mathrm{kV}$ and a frequency $f=86.2 \mathrm{kHz}$ employing the extended plasma-chemistry model of TMS (Tables 1,2). Here, a non-equidistant spatial grid using 250 intervals with logarithmically refined mesh towards the boundaries was employed. The temporal evolution of the discharge behavior was followed for the residence time $t_{\mathrm{r}}=V / F$ of the gas mixture in the plasma zone with a volume of $V=A \times d=0.8 \mathrm{~cm}^{3}$ including the effect of TMS depletion, where $t_{\mathrm{r}}=8 \mathrm{~ms}$, i.e., about 690 periods, for the gas flow rate $F=6 \mathrm{slm}$ in related experiments.

Fig. 6 Calculated temporal behavior of the discharge current at $U_{\mathrm{a}, 0}=4 \mathrm{kV}$ and $f=86.2 \mathrm{kHz}$ for the initial TMS fractions $x=10$ and 100 ppm in comparison with measured data
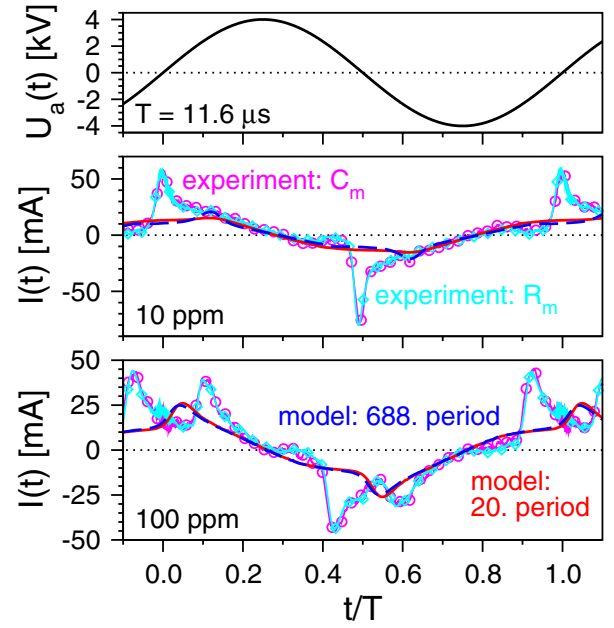
Figure 6 displays the applied voltage $U_{\mathrm{a}}(t)$ and the calculated temporal evolution of the discharge current

$$
I(t)=\frac{A}{d} \int_{0}^{d}\left[\varepsilon_{0} \frac{\partial}{\partial t} E(z, t)+e_{0} \sum_{j} Z_{j} \Gamma_{j}(z, t)\right] \mathrm{d} z
$$

for Ar-TMS mixtures with an initial fraction $x$ of TMS of 10 and $100 \mathrm{ppm}$, respectively, using the recommended total rate coefficient $k_{\mathrm{M}, \mathrm{Ar}^{*}}=3.0 \times 10^{-16} \mathrm{~m}^{3} / \mathrm{s}$ and Penning ionization fraction $\alpha_{\mathrm{Pl}}=0.25$ for the numerical modeling. Here, modeling results of the 20 . and 688. period are shown starting at the instants $t_{0}=0.23$ and $7.98 \mathrm{~ms}$ for $t / T=0$ in this figure. These results are compared with measured data of the periodic behavior of the discharge current. Here, the oscilloscope (MDO3052 from Tektronix, Beaverton, OR, USA) was used to monitor the voltage drop at the precision resistor $R_{\mathrm{M}}=1.00 \Omega$ or the measuring capacitor $C_{\mathrm{M}}=32.5 \mathrm{nF}$ (see Fig. 3), from which $I(t)$ or the transferred charge $Q(t)$ and, thus again the current $I(t)=\mathrm{d} Q(t) /(\mathrm{d} t)$, were obtained. A recent discussion related to measurements of the DBD actuator power consumption using the shunt resistor method and the monitor capacitor method, respectively, is given in [206].

There are quite different aspects which become obvious from Fig. 6. First of all, it can be seen that the measured and calculated discharge currents are of the same order of magnitude, where the results of both measurements using $R_{\mathrm{M}}$ and $C_{\mathrm{M}}$ agree fairly well. At the same time, the comparison of the measured current with the modeling results makes it clear that the measured temporal course of $I(t)$ cannot completely be reproduced by the model calculations. On the one hand, these differences can be attributed to the relatively large effect of electrode edges and the resulting fringing electric fields, which occur at the small-scale electrode configuration investigated with a length of only $1 \mathrm{~cm}$ in gas flow direction. For example, an experimental value of $6.6 \mathrm{pF}$ was obtained for the cell capacitance [33], a factor of 1.74 larger than that calculated using the equation for an ideal parallel-plate capacitor $(3.79 \mathrm{pF})$. Here, a spatially two-dimensional model is required. However, such model is currently not available and applicable because of the tremendous computational times to be expected, since the current timedependent, spatially one-dimensional model calculations including the complete ArTMS reaction kinetics already required about 4 months on a single CPU at $3.2 \mathrm{GHz}$ to reach $t_{\mathrm{r}}=8 \mathrm{~ms}$. In addition, the reason for the two discharge peaks per half-period found in the experiments at $x=100 \mathrm{ppm}$ with similar intensity in the positive half-period, but different intensity in the negative half-period is unclear so far.

On the other hand, the spatially one-dimensional modeling results provide helpful insights into the electrical characteristics as well as the reaction products and processes of DBDs in Ar-TMS mixtures. When comparing the modeling results of the 20. and 688. period for initially $x=100 \mathrm{ppm}$ TMS, it becomes clear that the calculated discharge current remains almost the same during the flow of the plasma across the discharge area, which lasts $t_{\mathrm{r}}=8 \mathrm{~ms}$ (Fig. 6). Here, the single discharge peak per half-period results to a large extent from Penning ionization due to collisions of excited argon atoms with TMS molecules. These Penning ionization processes are also the main source of electrons at the beginning of the calculated temporal evolution for $x=10 \mathrm{ppm}$ and lead to a comparatively small current peak (20. period), similar to the discharge current behavior in Ar-HMDSO mixtures discussed in [35]. At the end of the calculations around $t_{\mathrm{r}}=8 \mathrm{~ms}$ (688. period) the single peak of the discharge current per half-period is more pronounced and the temporal evolution of $I(t)$ shows great similarities to the behavior in 
pure Ar (cf. Figure 7 in [35]). This change of the calculated discharge current from the initial condition at $t=0$ to the end of the gas flow through the discharge area at $t_{\mathrm{r}}=8 \mathrm{~ms}$ is a direct consequence of the change of the composition of the discharge plasma and the corresponding change of dominant processes leading to the generation of electrons.

In order to illustrate the temporal change of the composition of the gas and of relevant species of the plasma during the residence time, Figs. 7, 8, 9 and 10 display results for various particle number densities obtained by model calculations for Ar-TMS mixtures with initially $x=10$ and 100 ppm TMS. Here, spatially averaged densities are shown. Furthermore, the spatially averaged mean energy of the electrons is represented in Fig. 9. Notice that the temporal evolution of period-averaged species densities and electron mean energy are exhibited to avoid a too noisy representation resulting from the temporal change during each period of duration $T=11.6 \mu \mathrm{s}$.

At initially $x=10 \mathrm{ppm}$ a drastic decrease of TMS is found during the temporal discharge development by a factor of 350 until $t_{\mathrm{r}}=8 \mathrm{~ms}$, i.e., TMS is virtually completely consumed at $t_{\mathrm{r}}$ (Fig. 7a). It leads mainly to the generation of methane $\left(\mathrm{CH}_{4}\right)$ and trimethylsilane $\left(\left(\mathrm{CH}_{3}\right)_{3} \mathrm{SiH}\right)$ during the first about $2 \mathrm{~ms}$ and predominantly to hydrogen molecules $\left(\mathrm{H}_{2}\right)$ in the later phase. Further stable molecules that are effectively generated and to be mentioned are ethylene $\left(\mathrm{C}_{2} \mathrm{H}_{4}\right)$, ethane $\left(\mathrm{C}_{2} \mathrm{H}_{6}\right)$, acetylene $\left(\mathrm{C}_{2} \mathrm{H}_{2}\right)$, and hexamethyldisilane $\left(\left(\mathrm{CH}_{3}\right)_{3} \mathrm{SiSi}\left(\mathrm{CH}_{3}\right)_{3}\right)$. Their production is a consequence of neutral-neutral collision processes involving radical species (Fig. 8a). Here, the primary radicals trimethylsilyl $\left(\left(\mathrm{CH}_{3}\right)_{3} \mathrm{Si}\right)$ and methyl $\left(\mathrm{CH}_{3}\right)$ are predominant at the beginning, while the hydrogen atom becomes leading for times greater than about $2 \mathrm{~ms}$. In addition to several hydrocarbon radicals, further silicon-containing radicals, namely dimethylsilyl $\left(\left(\mathrm{CH}_{3}\right)_{2} \mathrm{SiH}\right)$, dimethylsilylene $\left(\left(\mathrm{CH}_{3}\right)_{2} \mathrm{Si}\right)$, [dimethyl(trimethylsilyl)silyl]methyl $\left(\left(\mathrm{CH}_{3}\right)_{3} \mathrm{SiSi}\left(\mathrm{CH}_{3}\right)_{2} \mathrm{CH}_{2}\right)$, methylsilanylidyne $\left(\left(\mathrm{CH}_{3}\right) \mathrm{Si}\right)$, and methylsilyl $\left(\left(\mathrm{CH}_{3}\right) \mathrm{SiH}_{2}\right)$, are also formed during the temporal evolution and also still have a remarkable number density in some cases at $t_{\mathrm{r}}=8 \mathrm{~ms}$, such as $\left(\mathrm{CH}_{3}\right)_{2} \mathrm{SiH}$.

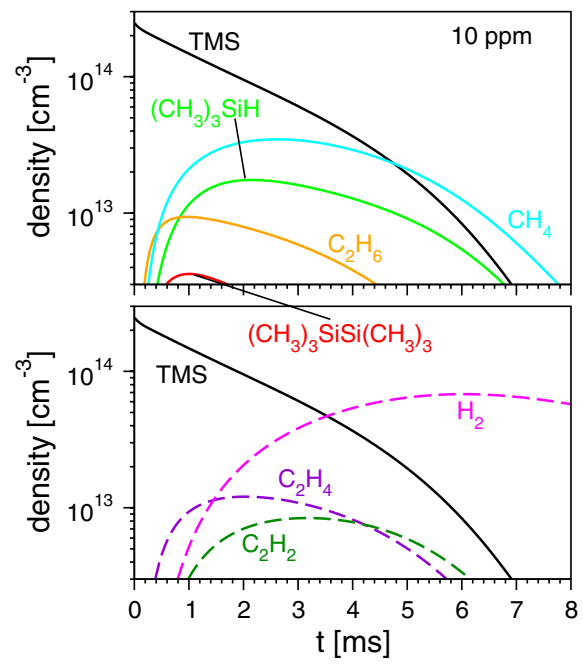

(a)

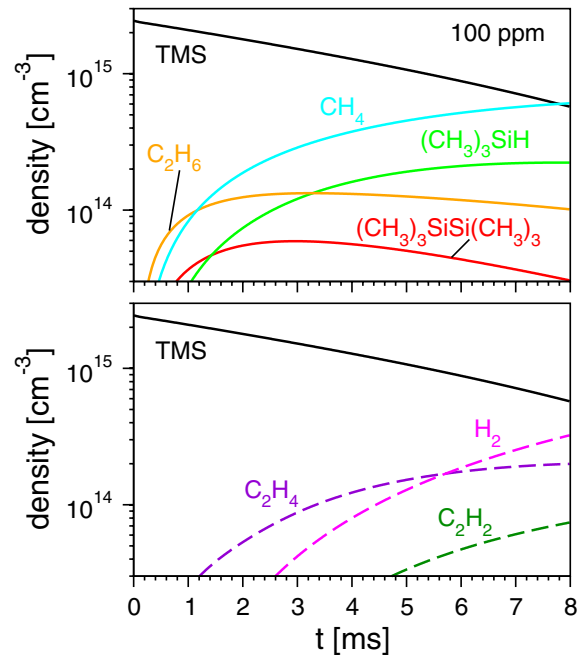

(b)

Fig. 7 Temporal evolution of particle densities of stable molecules for $U_{\mathrm{a}, 0}=4 \mathrm{kV}, f=86.2 \mathrm{kHz}$, and the initial TMS fraction, $\mathbf{a} x=10 \mathrm{ppm}$ and $\mathbf{b} x=100 \mathrm{ppm}$ 


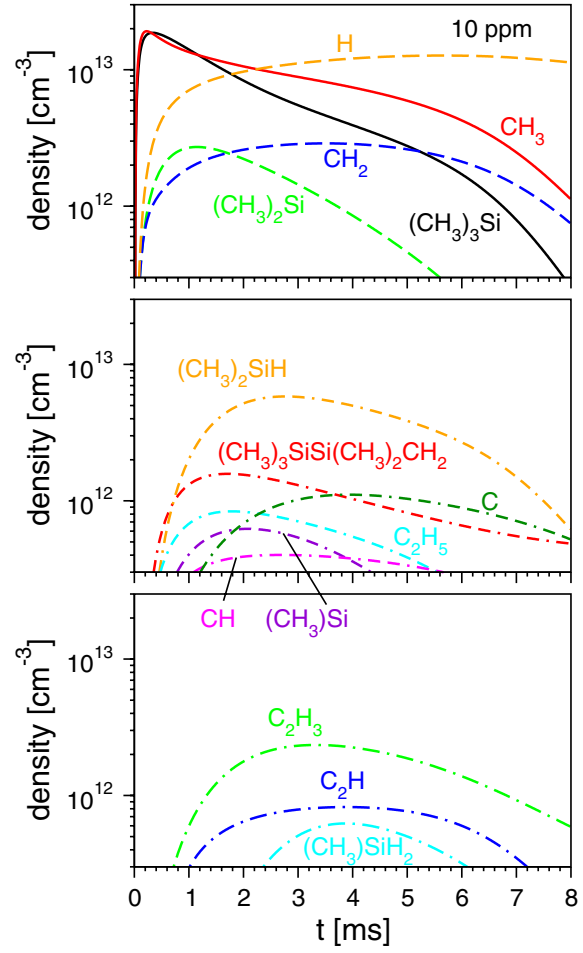

(a)

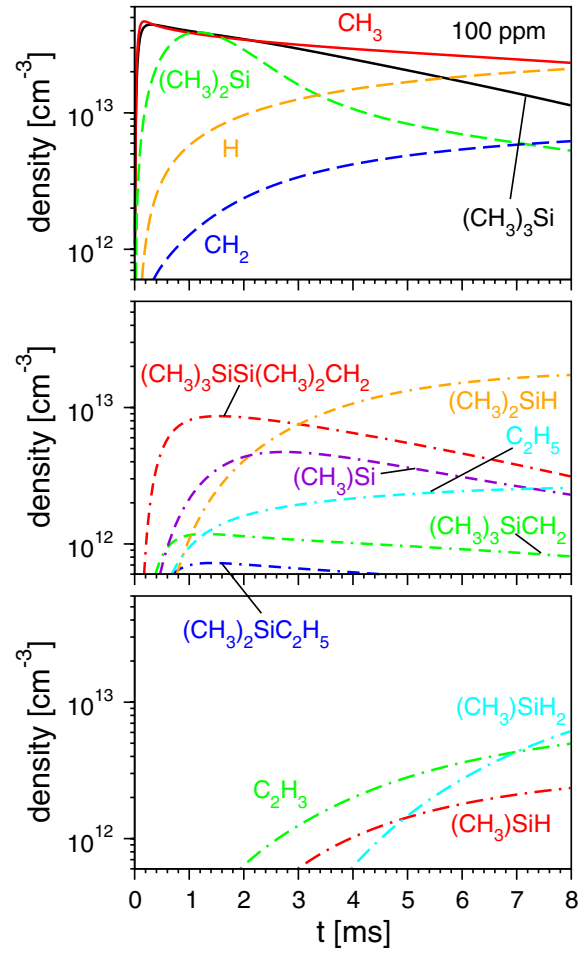

(b)

Fig. 8 Temporal evolution of particle densities as in Fig. 7 but for radical species

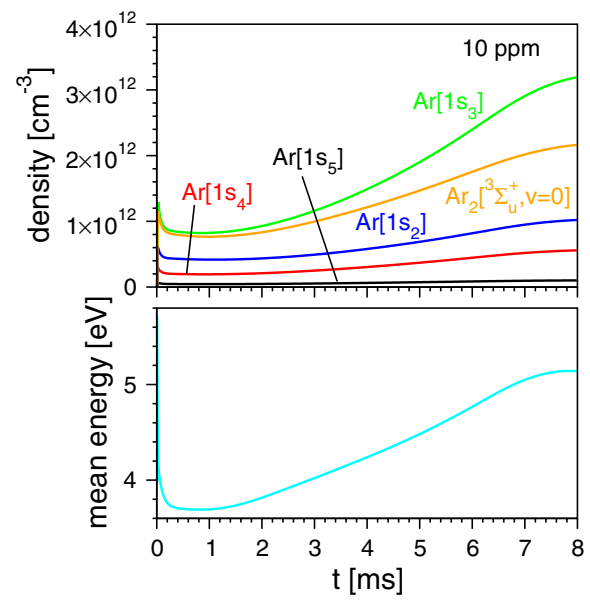

(a)

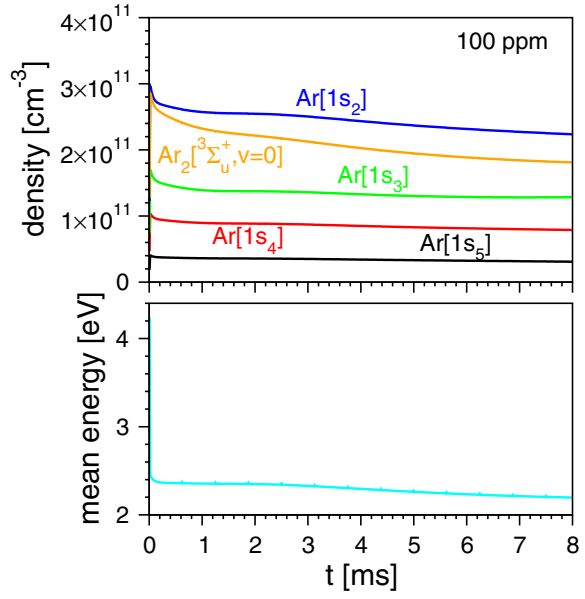

(b)

Fig. 9 Temporal evolution as in Fig. 7 but for particle densities of excited argon species and the mean electron energy 


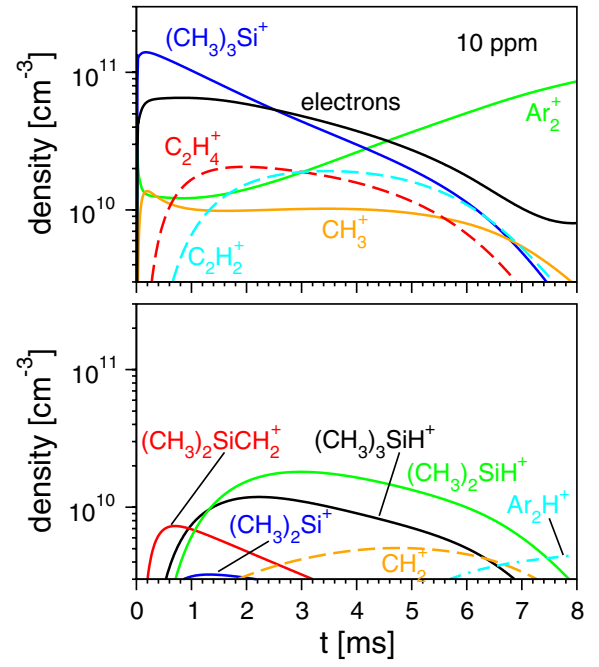

(a)

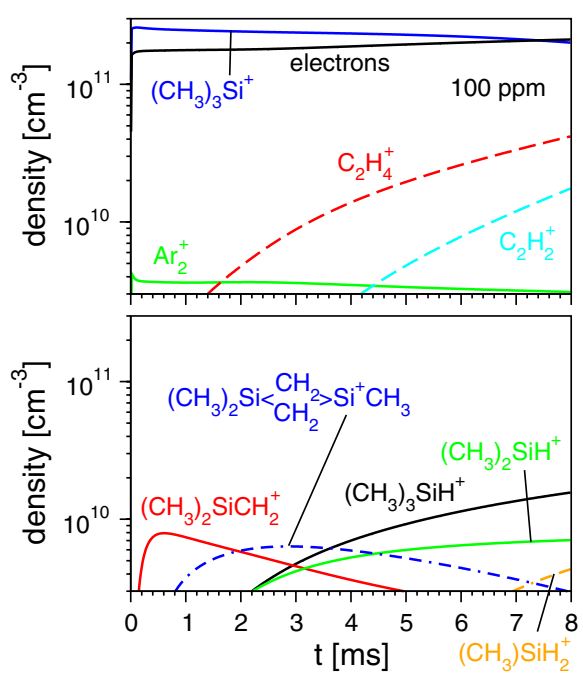

(b)

Fig. 10 Temporal evolution of particle densities as in Fig. 7 but for charge carriers

The decrease of TMS is primarily caused by collisional quenching in collisions with excited argon species (Fig. 9a), predominantly by metastable $\operatorname{Ar}\left[1 \mathrm{~s}_{3}\right]$ atoms and the excimer $\operatorname{Ar}_{2}\left[{ }^{3} \Sigma_{u}^{+}, v=0\right]$, followed by the resonance $\operatorname{Ar}\left[1 s_{2}\right]$ and $\operatorname{Ar}\left[1 s_{4}\right]$ atoms. Here, $25 \%$ of the collision processes of excited argon atoms with TMS each lead to the generation of an electron, a trimethylsilyl cation, a methyl radical, and $\operatorname{Ar}\left[1 \mathrm{p}_{0}\right]$ due to Penning ionization (Fig. 10a). Measurements of particle number densities of metastable and resonance argon atoms could help to confirm the predictions about their absolute value and relative contribution predicted by the model.

When keeping in mind that the background gas density of ground state argon atoms is $2.45 \times 10^{19} \mathrm{~cm}^{-3}$ and that $\mathrm{H}_{2}, \mathrm{CH}_{4}$, and $\mathrm{C}_{2} \mathrm{H}_{6}$ are not able to generate electrons due to Penning ionization processes with excited argon atoms, it is immediately clear that the discharge current behavior has to change in the course of time from an initially Penning ionization dominated one to a behavior predominantly determined by electronimpact ionization of $\operatorname{Ar}\left[1 \mathrm{p}_{0}\right]$ atoms at initially $x=10 \mathrm{ppm}$ (cf. Fig. 6). This transition is continuously supported by the increase of the mean electron energy leading to an increase of the number densities of excited argon species (Fig. 9a). At the same time the electron density decreases and molecular argon ions become the leading charge carrier (Fig. 10a). Negative ions play a negligible role for the discharge behavior, where the most prominent one, $\left(\mathrm{CH}_{3}\right)_{3} \mathrm{Si}^{-}$, has a number density of $\leq 10^{8} \mathrm{~cm}^{-3}$ during the entire temporal evolution. Here, it has to be noted that all silicon-containing and hydrocarbon cations are generated to a certain extent due to Penning ionization processes, while the $\mathrm{Ar}_{2} \mathrm{H}^{+}$ion results from charge-transfer reactions of $\mathrm{Ar}_{2}^{+}$with $\mathrm{H}_{2}$ molecules. Note further that quasi-neutrality is limited to the main discharge phase and exists only in the plasma bulk region. Due to the applied sinusoidal voltage, electrons drift fast to the dielectric walls where they are partly lost. Hence electron-ion recombination plays a minor role for the discharge behavior. Thus, the sum of space- and period-averaged number densities of all cations exceeds that of electrons plus all anions as it becomes obvious from Fig. 10. 
When looking at the modeling results for the initial TMS fraction $x=100 \mathrm{ppm}$, the almost same behavior of the discharge current at the 20. and 688. period (cf. Fig. 6) indicates that a quite different temporal evolution of the various particle number densities and the mean electron energy can be expected. Their development during the residence time $t_{\mathrm{r}}=8 \mathrm{~ms}$ is shown in part b of Figs. 7, 8, 9 and 10.

Again, TMS decreases mainly due to collisions with excited argon species, but the reduction of TMS is by about $75 \%$ only (Fig. 7b). Further modeling results show that, for instance, TMS reduces by $90 \%$ at initially $x=50 \mathrm{ppm}$, while $50 \%$ of the monomer remain after $t_{\mathrm{r}}=8 \mathrm{~ms}$ at $x=200 \mathrm{ppm}$. This finding agrees well with the analysis provided by [30], where the consumption of TMS in an atmospheric-pressure Ar-TMS microplasma was found to be more effective at low TMS concentrations compared with their consumptions at high concentrations. A similar trend of monomer depletion in a large-area atmosphericpressure DBD in Ar-HMDSO mixtures was recently discussed in [37]. This decrease of the percentage monomer consumption during the residence time of the plasma in the discharge with increasing monomer fraction is a direct consequence of the finite number of excited argon species available to dissociate and/or ionize the monomer via energy transfer.

The main stable molecules generated in the Ar-TMS DBD for initially $x=100 \mathrm{ppm}$ are the same as for $x=10 \mathrm{ppm}$ (Fig. 7). However, the composition of the plasma is different. Here, methane becomes the predominant species at $t_{\mathrm{r}}=8 \mathrm{~ms}$, except for the background ground gas argon with a number density of $2.45 \times 10^{19} \mathrm{~cm}^{-3}$. After TMS, molecular hydrogen, trimethylsilane, and ethylene follow. Since the latter two species as well as acetylene and hexamethyldisilane are also able to generated electrons due to collision processes with excited argon atoms, about $40 \%$ of the species relevant to the TMS kinetics contribute to Penning ionization at $t_{\mathrm{r}}=8 \mathrm{~ms}$. Furthermore it should be mentioned that further silicon-containing stable molecules are generated during the temporal evolution, which reach particle number densities above $3 \times 10^{13} \mathrm{~cm}^{-3}$. These species are 1,1-dimethylsilirane, 1,1-dimethylsilirene, 1,1,1,2,2,3,3-heptamethyltrisilane, ethylpentamethyldisilane, and pentamethyl[(trimethylsilyl)methyl]disilane (cf. Table 3) and their space- and periodaveraged particle number densities at $t_{\mathrm{r}}=8 \mathrm{~ms}$ amount to $2.2 \times 10^{14} \mathrm{~cm}^{-3}, 8.6 \times 10^{13} \mathrm{~cm}^{-3}$, $6.3 \times 10^{13} \mathrm{~cm}^{-3}, 5.3 \times 10^{13} \mathrm{~cm}^{-3}$, and $4.5 \times 10^{13} \mathrm{~cm}^{-3}$, respectively. However, they are only generated in the framework of the present reaction kinetics model and do not have any collisional loss process so that these values appear to be upper limits.

Most of the radical species already found at $x=10 \mathrm{ppm}$ are also generated at the initial TMS fraction of $100 \mathrm{ppm}$ (Fig. 8b). However, the share of these species changes, where in particular the amount and particle number density of silicon-containing radicals increases. In addition to trimethylsilyl, dimethylsilylene, dimethylsilyl, and [dimethyl(trimethylsilyl) silyl]methyl are effectively formed during the temporal evolution. Furthermore, methylsilanylidyne and methylsilyl as well as (trimethylsilyl)methyl and methylsilylene are formed (cf. Table 3), where the latter two species are not present at initially $x=10 \mathrm{ppm}$. Moreover, methyl is the predominant hydrocarbon radical, and hydrogen atoms are again generated to a considerable extent (Fig. 8b).

When comparing the excited argon species at $x=10$ and 100 ppm (Fig. 9), it becomes obvious that the more effective quenching due to collisions with TMS at the larger TMS admixture leads to a decrease of the absolute number densities of these species by about one order of magnitude. For initially $x=100 \mathrm{ppm}$, the resonance $\operatorname{Ar}\left[1 \mathrm{~s}_{2}\right]$ atom is largest, followed by the excimer $\operatorname{Ar}_{2}\left[{ }^{3} \Sigma_{\mathrm{u}}^{+}, \mathrm{v}=0\right]$ and the sequence of the further $\operatorname{Ar}\left[1 \mathrm{~s}_{\mathrm{j}}\right]$ levels with $j=3-5$ decreasing with increasing $j$, i.e., decreasing energy level (Fig. 9b). At the same time, the number density of all these particles shows a monotonous reduction, which comes along with the slight decrease of the mean electron energy. 
Despite the slow decline of their mean energy, the space- and period-averaged number density of electrons rises steadily, mainly due to Penning ionization processes of excited argon atoms, where the trimethylsilyl cation is the main ionic species during the entire temporal evolution (Fig. 10b). Except for ethylene and acetylene ions, the number densities of all other ions remain smaller by more than one order of magnitude than that of $\left(\mathrm{CH}_{3}\right)_{3} \mathrm{Si}^{+}$. In addition to the dimethylmethylenesilane, trimethylsilane and dimethylsilyl cations, the methylsilyl ion and especially the 1,1,3-trimethyl-1,3-disilacyclobutane-1-yl ion with a mass to charge ratio of 129 are predicted by the model calculations (cf. Table 4). The latter originates from collision processes of 1,1,3,3-tetramethyl-1,3-disilacyclobutane (Table 3) mainly with excited argon atoms leading to Penning ionization. Notice that several of the positive ions were also reported in the studies of an atmospheric-pressure microplasma with Ar-TMS containing 280, 1600, and $3500 \mathrm{ppm}$, respectively, of TMS [30]. These are the ions with the nominal mass $M / Z 15,26,28,45,58,59,73$, and 129 (cf. Table 4). However, the silicon-containing trimethylsilane ion $(M / Z=74)$ and dimethylmethylenesilane ion $(M / Z=72)$ (Fig. 10) were not found in that study. Again, the particle number densities of all negative ions remain small in the Ar-TMS DBD with initially $x=100 \mathrm{ppm}$, namely $\leq 10^{9} \mathrm{~cm}^{-3}, 2 \times 10^{8} \mathrm{~cm}^{-3}$, and $3 \times 10^{7} \mathrm{~cm}^{-3}$ for $\left(\mathrm{CH}_{3}\right)_{3} \mathrm{Si}^{-}, \mathrm{H}^{-}$, and $\mathrm{CH}_{2}^{-}$, respectively.

The results for the number densities of radicals and charge carriers obtained by numerical modeling (Figs. 8 and 10) suggest that radicals are the predominant species for the film formation in plasma polymerization at atmospheric pressure [24]. Corresponding argumentations are also given when discussing the deposition of thin films using atmospheric-pressure DBDs with admixture of the monomers HMDSO or tetraethoxysilane (TEOS) [13, 33, 35, 207-210]. However, not the particle number density is the key for the film formation, but the flux of particles towards the surface. In order to get an impression of main particle fluxes at the dielectric surface at $z_{0}=d$ in front of the grounded electrode (cf. Fig. 1b), Fig. 11 shows the temporal evolution of the particle fluxes of main radicals and charge carriers. Here, period-averaged fluxes $\left\langle\Gamma_{j}(d, t)\right\rangle_{T}$ are displayed for the initial TMS fractions

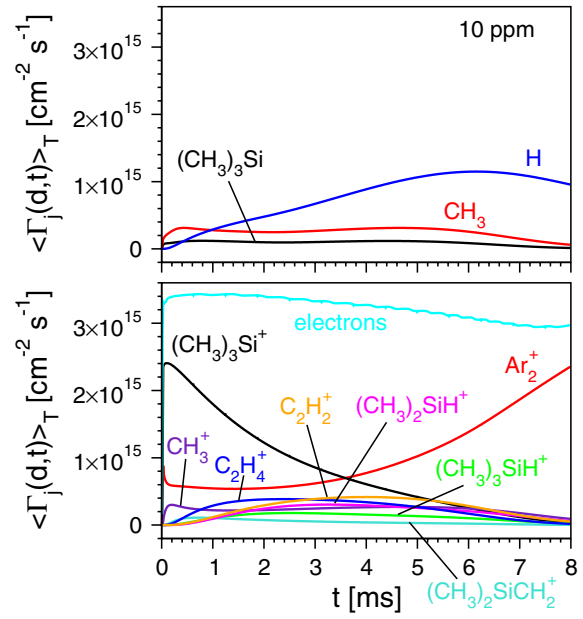

(a)

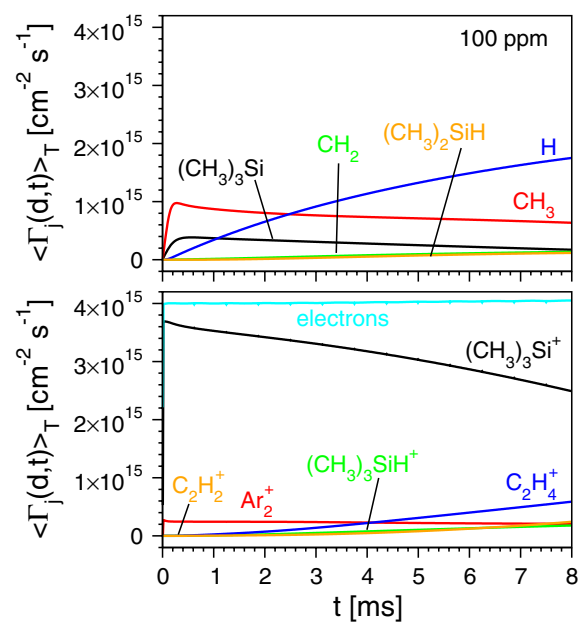

(b)

Fig. 11 Temporal evolution of particle flux of radicals and charge carriers at the boundary $z_{0}=d$ for $U_{\mathrm{a}, 0}=4 \mathrm{kV}, f=86.2 \mathrm{kHz}$, and the initial TMS fraction, $\mathbf{a} x=10 \mathrm{ppm}$ and $\mathbf{b} x=100 \mathrm{ppm}$ 
$x=10$ and $100 \mathrm{ppm}$. Apart from the electrons, the flux of trimethylsilyl cations is predominant at $x=100 \mathrm{ppm}$ and at beginning of the temporal evolution at $x=10 \mathrm{ppm}$ as well. Moreover, the $\left(\mathrm{CH}_{3}\right)_{3} \mathrm{Si}^{+}$flux is always larger than the flux of the most prominant siliconcontaining radial $\left(\mathrm{CH}_{3}\right)_{3} \mathrm{Si}$, where larger TMS fractions result in an increasing dominance of the flux of positive trimethylsilyl ions. This finding means that ions and not radicals are mainly responsible for the film formation in atmospheric-pressure plasma polymerization using DBDs with Ar-TMS mixtures.

\section{Conclusion}

The impact on the discharge characteristics of atmospheric-pressure argon DBDs caused by admixing up to $200 \mathrm{ppm}$ TMS has been analyzed by means of a time-dependent, spatially one-dimensional fluid-Poisson model. It involves, in particular, an established reaction kinetics scheme for argon and an extended plasma-chemistry model including about 60 species and 580 reactions related to TMS.

Based on good agreement of modeling results with corresponding measurements of the ignition voltage, it is found that the rate coefficient for collision processes of TMS with excited $\operatorname{Ar}\left[1 \mathrm{~s}_{5}\right]$ atoms [57] and the fraction leading to Penning ionization [57, 59] are underestimated so far. Best agreement between measured and calculated data is obtained for a total collision rate coefficient of TMS with excited argon atoms of $3 \times 10^{-16} \mathrm{~m}^{3} / \mathrm{s}$, assuming that $25 \%$ of that reaction lead to the generation of electrons due to Penning ionization.

The numerical modeling studies clearly demonstrate the significant impact of small amounts of TMS on the temporal behavior of Ar-TMS DBDs operating under conditions typical of deposition experiments. It is found that TMS is largely depleted at low admixtures, while a growing amount of this monomer remains available for film formation with increasing TMS admixture. Trimethylsilane and hexamethyldisilane are found to be the major silicon-containing stable molecules generated during the residence time of the plasma in the $\mathrm{DBD}$, and trimethylsilyl, dimethylsilylene, dimethylsilane, and [dimethyl(trimethylsilyl)silyl]methyl are the most prominent radicals containing Si.

The analysis clearly indicates as well that trimethylsilyl cations can be considered to be mainly responsible for the film formation. This result is strongly supported by first experimental results related to a single-filament DBD in Ar-HMDSO mixtures, where pentamethyldisiloxanyl cations, generated from HMDSO via Penning ionization due to collisions with excited argon atoms, are found to be the dominant species to form the film [211]. Thus, the present modeling studies raise the serious question, if the current knowledge of the processes leading to the formation of organosilicon films has to be reconsidered or revised. Further combined experimental and modeling studies on that finding can help to clarify the fundamental understanding of main species and reaction pathways for the formation of organosilicon polymer films.

Acknowledgements The work was partly funded by the Deutsche Forschungsgemeinschaft (DFG, German Research Foundation)_-project numbers 5451831, 213099213, and 213099267. The authors thank J. Philipp very much for his assistance in the electrical measurements.

Funding Open Access funding provided by Projekt DEAL. 
Data Availability The datasets related to the comparison between modeling and experimental results shown in Figs. 4 and 6 are available in the research data platform INPTDAT [212]. Further datasets generated and analyzed during the current study are available from the corresponding author on reasonable request.

Open Access This article is licensed under a Creative Commons Attribution 4.0 International License, which permits use, sharing, adaptation, distribution and reproduction in any medium or format, as long as you give appropriate credit to the original author(s) and the source, provide a link to the Creative Commons licence, and indicate if changes were made. The images or other third party material in this article are included in the article's Creative Commons licence, unless indicated otherwise in a credit line to the material. If material is not included in the article's Creative Commons licence and your intended use is not permitted by statutory regulation or exceeds the permitted use, you will need to obtain permission directly from the copyright holder. To view a copy of this licence, visit http://creativecommons.org/licenses/by/4.0/.

\section{References}

1. Tajima I, Yamamoto M (1987) J Polym Sci A Polym Chem 25(7):1737. https://doi.org/10.1002/ pola.1987.080250703

2. Wróbel AM, Czeremuszkin G, Szymanowski H, Kowalski J (1990) Plasma Chem Plasma Process 10(2):277. https://doi.org/10.1007/BF01447131

3. Favia P, Lamendola R, d'Agostino R (1992) Plasma Sources Sci Technol 1(1):59. https://doi. org/10.1088/0963-0252/1/1/007

4. Zhang W, Lelogeais M, Ducarroir M (1992) Jpn J Appl Phys 31(12R):4053. https://doi. org/10.1143/JJAP.31.4053

5. Peter S, Pintaske R, Hecht G, Richter F (1993) Surf Coat Technol 59(1):97. https://doi. org/10.1016/0257-8972(93)90061-R

6. Fonseca JLC, Apperley DC, Badyal JPS (1993) Chem Mater 5(11):1676. https://doi.org/10.1021/ $\mathrm{cm} 00035 \mathrm{a} 015$

7. Grill A, Patel V (1999) J Appl Phys 85(6):3314. https://doi.org/10.1063/1.369677

8. Han LM, Pan JS, Chen S-M, Balasubramanian N, Shi J, Wong LS, Foo PD (2001) J Electrochem Soc 148(7):F148. https://doi.org/10.1149/1.1375797

9. Yanguas-Gil Á, Barranco Á, Cotrino J, Gröning P, González-Elipe AR (2006) Chem Vap Depos 12(12):728. https://doi.org/10.1002/cvde.200606496

10. Soum-Glaude A, Thomas L, Tomasella E (2006) Surf Coat Technol 200(22):6425. https://doi. org/10.1016/j.surfcoat.2005.11.066

11. Kihel M, Sahli S, Zenasni A, Raynaud P, Segui Y (2014) Vacuum 107:264. https://doi. org/10.1016/j.vacuum.2014.02.022

12. Kurunczi P, Koharian A, Becker K, Martus K (1996) Contrib Plasma Phys 36(6):723. https://doi. org/10.1002/ctpp.2150360608

13. Sonnenfeld A, Tun TM, Zajíčková L, Kozlov KV, Wagner H-E, Behnke JF, Hippler R (2001) Plasmas Polym 6(4):237. https://doi.org/10.1023/A:1014414016164

14. Ipolyi I, Burean E, Hamann T, Cingel M, Matejcik S, Swiderek P (2009) Int J Mass Spectrom 282(3):133. https://doi.org/10.1016/j.ijms.2009.02.020

15. Lide DR (ed) (2009) CRC handbook of chemistry and physics, 90th edn. CRC Press, Boca Raton

16. Rynders SW, Scheeline A, Bohn PW (1991) J Appl Phys 69(5):2951. https://doi. org/10.1063/1.348606

17. Fonseca JLC, Tasker S, Apperley DC, Badyal JPS (1996) Macromolecules 29(5):1705. https://doi. org/10.1021/ma950222v

18. Thomas L, Maillé L, Badie JM, Ducarroir M (2001) Surf Coat Technol 142-144:314. https://doi. org/10.1016/S0257-8972(01)01081-7

19. Soum-Glaude A, Thomas L, Dollet A, Picard C (2007) Plasma Process Polym 4(1):S11. https:// doi.org/10.1002/ppap.200730201

20. Soum-Glaude A, Thomas L, Dollet A, Ségur P, Bordage M-C (2007) Diam Relat Mater 16(4):1259. https://doi.org/10.1016/j.diamond.2006.11.003

21. Massines F, Sarra-Bournet C, Fanelli F, Naudé N, Gherardi N (2012) Plasma Process Polym 9(1112):1041. https://doi.org/10.1002/ppap.201200029

22. Merche D, Vandencasteele N, Reniers F (2012) Thin Solid Films 520(13):4219. https://doi. org/10.1016/j.tsf.2012.01.026 
23. Raballand V, Benedikt J, von Keudell A (2008) Appl Phys Lett 92(9):091502. https://doi. org/10.1063/1.2844880

24. Marchand DJ, Dilworth ZR, Stauffer RJ, Hsiao E, Kim J-H, Kang J-G, Kim SH (2013) Surf Coat Technol 234:14. https://doi.org/10.1016/j.surfcoat.2013.03.029

25. Kwong CH, Ng SP, Kan CW, Molina R (2014) Fibers Polym 15(8):1596. https://doi.org/10.1007/ s12221-014-1596-7

26. Kan CW, Kwong CH, Ng SP (2015) Appl Surf Sci 346:270. https://doi.org/10.1016/j.apsus c. 2015.03 .111

27. Kan CW, Kwong CH, Ng SP (2015) Fibers Polym 16(3):702. https://doi.org/10.1007/s1222 1-015-0702-9

28. Kan C-W, Kwong C-H, Ng S-P (2016) Appl Sci 6(2):59. https://doi.org/10.3390/app6020059

29. Kan CW, Kwong CH, Ng SP (2016) J Text Inst 107(1):91. https://doi.org/10.1080/00405 000.2015 .1012880

30. Haq AU, Lucke P, Benedikt J, Maguire P, Mariotti D (2020) Plasma Process Polym 17(5):1900243. https://doi.org/10.1002/ppap.201900243

31. Kogelschatz U (2003) Plasma Chem Plasma Process 23(1):1. https://doi.org/10.1023/A:10224 70901385

32. Philipp J, Czerny AK, Klages C-P (2016) Plasma Process Polym 13(5):509. https://doi. org/10.1002/ppap.201500136

33. Klages C-P, Czerny AK, Philipp J, Becker MM, Loffhagen D (2017) Plasma Process Polym 14(12):1700081. https://doi.org/10.1002/ppap.201700081

34. Becker MM, Hoder T, Brandenburg R, Loffhagen D (2013) J Phys D Appl Phys 46(35):355203. https://doi.org/10.1088/0022-3727/46/35/355203

35. Loffhagen D, Becker MM, Czerny AK, Philipp J, Klages C-P (2018) Contrib Plasma Phys 58(5):337. https://doi.org/10.1002/ctpp.201700060

36. Fridman A (2008) Plasma chemistry. Cambridge University Press, New York

37. Loffhagen D, Becker MM, Hegemann D, Nisol B, Watson S, Wertheimer MR, Klages C-P (2020) Plasma Process Polym 17(2):1900169. https://doi.org/10.1002/ppap.201900169

38. Höft H, Kettlitz M, Becker MM, Hoder T, Loffhagen D, Brandenburg R, Weltmann K-D (2014) J Phys D Appl Phys 47(46):465206. https://doi.org/10.1088/0022-3727/47/46/465206

39. Ponduri S, Becker MM, Welzel S, van de Sanden MCM, Loffhagen D, Engeln R (2016) J Appl Phys 119(9):093301. https://doi.org/10.1063/1.4941530

40. Becker MM, Loffhagen D (2013) AIP Adv 3:012108. https://doi.org/10.1063/1.4775771

41. Becker MM, Kählert H, Sun A, Bonitz M, Loffhagen D (2017) Plasma Sources Sci Technol 26(4):044001. https://doi.org/10.1088/1361-6595/aa5cce

42. Leyh H, Loffhagen D, Winkler R (1998) Comput Phys Commun 113(1):33. https://doi. org/10.1016/S0010-4655(98)00062-9

43. Vass M, Korolov I, Loffhagen D, Pinhão N, Donkó Z (2017) Plasma Sources Sci Technol 26(6):065007. https://doi.org/10.1088/1361-6595/aa6789

44. Perrin J, Leroy O, Bordage M-C (1996) Contrib Plasma Phys 36(1):3. https://doi.org/10.1002/ ctpp. 2150360102

45. Bordage M-C (2007) Plasma Sci Technol 9(6):756. https://doi.org/10.1088/1009-0630/9/6/28

46. Ali MA, Kim Y-K, Hwang W, Weinberger NM, Rudd ME (1997) J Chem Phys 106(23):9602. https://doi.org/10.1063/1.473842

47. Peart B, Forrest R, Dolder KT (1979) J Phys B At Mol Phys 12(3):L115. https://doi. org/10.1088/0022-3700/12/3/009

48. Walton DS, Peart B, Dolder KT (1971) J Phys B At Mol Phys 4(10):1343. https://doi. org/10.1088/0022-3700/4/10/019

49. Peart B, Forrest R, Dolder KT (1979) J Phys B At Mol Phys 12(5):847. https://doi. org/10.1088/0022-3700/12/5/028

50. http://www.chemicalize.org (2018)

51. Velazco JE, Kolts JH, Setser DW (1978) J Chem Phys 69(10):4357. https://doi. org/10.1063/1.436447

52. Oka T, Kogoma M, Imamura M, Arai S, Watanabe T (1979) J Chem Phys 70(7):3384. https://doi. org/10.1063/1.437923

53. Carles S, Le Garrec JL, Mitchell JBA (2007) J Chem Phys 127(14):144308. https://doi. org/10.1063/1.2774984

54. Bardsley JN, Biondi MA (1970) Advances in atomic and molecular physics, vol 6. Academic Press, New York 
55. Johnston DR, Oudemans GJ, Cole RH (1960) J Chem Phys 33(5):1310. https://doi. org $/ 10.1063 / 1.1731405$

56. Hickman AP (1979) J Chem Phys 70(11):4872. https://doi.org/10.1063/1.437364

57. Jauberteau JL, Jauberteau I, Aubreton J (2000) Chem Phys Lett 327(5):351. https://doi. org/10.1016/S0009-2614(00)00854-X

58. Jauberteau JL, Jauberteau I (2012) J Phys Chem A 116(35):8840. https://doi.org/10.1021/jp304694z

59. Anderson DR, Bierbaum VM, Depuy CH, Grabowski JJ (1983) Int J Mass Spectrom Ion Phys 52(1):65. https://doi.org/10.1016/0020-7381(83)85092-X

60. Creatore M, Barrell Y, Benedikt J, van de Sanden MCM (2006) Plasma Sources Sci Technol 15(3):421. https://doi.org/10.1088/0963-0252/15/3/018

61. Wetzel DM, Salomon KE, Berger S, Brauman JI (1989) J Am Chem Soc 111(11):3835. https://doi. org/10.1021/ja00193a013

62. Thomson JJ (1912) Philos Mag 23(136):449. https://doi.org/10.1080/14786440408637241

63. Rudge MRH (1964) Proc Phys Soc 83(3):419. https://doi.org/10.1088/0370-1328/83/3/309

64. Viehland LA, Mason EA (1995) At Data Nucl Data Tables 60(1):37. https://doi.org/10.1006/ adnd.1995.1004

65. Deutsch H, Becker K, Basner R, Schmidt M, Märk TD (1998) J Phys Chem A 102(45):8819. https:// doi.org/10.1021/jp9827577

66. Bell KL, Gilbody HB, Hughes JG, Kingston AE, Smith FJ (1983) J Phys Chem Ref Data 12(4):891. https://doi.org/10.1063/1.555700

67. Shah MB, Elliott DS, Gilbody HB (1987) J Phys B At Mol Phys 20(14):3501. https://doi. org/10.1088/0022-3700/20/14/022

68. Freund RS, Wetzel RC, Shul RJ, Hayes TR (1990) Phys Rev A 41:3575. https://doi.org/10.1103/ PhysRevA.41.3575

69. Kim Y-K, Stone PM (2007) J Phys B At Mol Opt Phys 40(8):1597. https://doi. org/10.1088/0953-4075/40/8/011

70. Jiao CQ, Garscadden A, Haaland PD (1999) Int J Mass Spectrom 184(1):83. https://doi.org/10.1016/ S1387-3806(98)14270-7

71. Hwang W, Kim Y-K, Rudd ME (1996) J Chem Phys 104(8):2956. https://doi.org/10.1063/1.471116

72. Straub HC, Lin D, Lindsay BG, Smith KA, Stebbings RF (1997) J Chem Phys 106(11):4430. https:// doi.org/10.1063/1.473468

73. Kim Y-K, Ali MA, Rudd ME (1997) J Res Natl Inst Stand Technol 102(6):693. https://doi. org/10.6028/jres. 102.046

74. Chatham H, Hils D, Robertson R, Gallagher A (1984) J Chem Phys 81(4):1770. https://doi. org/10.1063/1.447848

75. Nishimura H, Tawara H (1994) J Phys B At Mol Opt Phys 27(10):2063. https://doi. org/10.1088/0953-4075/27/10/016

76. Song M-Y, Yoon J-S, Cho H, Karwasz GP, Kokoouline V, Nakamura Y, Tennyson J (2017) J Phys Chem Ref Data 46(1):013106. https://doi.org/10.1063/1.4976569

77. Yoon J-S, Song M-Y, Han J-M, Hwang SH, Chang W-S, Lee B, Itikawa Y (2008) J Phys Chem Ref Data 37(2):913. https://doi.org/10.1063/1.2838023

78. Peart B, Walton DS, Dolder KT (1970) J Phys B At Mol Phys 3(10):1346. https://doi. org/10.1088/0022-3700/3/10/012

79. Rawat P, Prabhudesai VS, Rahman MA, Bhargava Ram N, Krishnakumar E (2008) Int J Mass Spectrom 277(1):96. https://doi.org/10.1016/j.ijms.2008.05.015

80. Song M-Y, Yoon J-S, Cho H, Itikawa Y, Karwasz GP, Kokoouline V, Nakamura Y, Tennyson J (2015) J Phys Chem Ref Data 44(2):023101. https://doi.org/10.1063/1.4918630

81. Shishikura Y, Asano K, Nakamura Y (1997) J Phys D Appl Phys 30(11):1610. https://doi. org/10.1088/0022-3727/30/11/010

82. Rutkowsky J, Drost H, Spangenberg H-J (1980) Ann Phys 492(4):259. https://doi.org/10.1002/ andp. 19804920404

83. May O, Fedor J, Allan M (2009) Phys Rev A 80:012706. https://doi.org/10.1103/PhysRevA.80.01270 6

84. Ehrhardt AB, Langer WD (1987) Collisional processes of hydrocarbons in hydrogen plasmas. Tech. Rep. PPPL-2477, Plasma Physics Laboratory, Princeton University, Princeton, New Jersey 08544, USA

85. Nakano T, Toyoda H, Sugai H (1991) Jpn J Appl Phys 30(11R):2908. https://doi.org/10.1143/ JJAP. 30.2908

86. Nakano T, Toyoda H, Sugai H (1991) Jpn J Appl Phys 30(11R):2912. https://doi.org/10.1143/ JJAP.30.2912 
87. Janev RK, Reiter D (2004) Phys Plasmas 11(2):780. https://doi.org/10.1063/1.1630794

88. Shul RJ, Upschulte BL, Passarella R, Keesee RG, Castleman AW (1987) J Phys Chem 91(10):2556. https://doi.org/10.1021/j100294a022

89. Praxmarer C, Hansel A, Lindinger W, Herman Z (1998) J Chem Phys 109(11):4246. https://doi. org/10.1063/1.477073

90. Tsuji M, Kouno H, Matsumura K, Funatsu T, Nishimura Y, Obase H, Kugishima H, Yoshida K (1993) J Chem Phys 98(3):2011. https://doi.org/10.1063/1.464234

91. Dotan I, Lindinger W (1982) J Chem Phys 76(10):4972. https://doi.org/10.1063/1.442843

92. Adams NG, Bohme DK, Ferguson EE (1970) J Chem Phys 52(10):5101. https://doi. org/10.1063/1.1672748

93. Potzinger P, Lampe FW (1971) J Phys Chem 75(1):13. https://doi.org/10.1021/j100671a002

94. Phelps AV (1992) J Phys Chem Ref Data 21(4):883. https://doi.org/10.1063/1.555917

95. Jones EG, Harrison AG (1970) Int J Mass Spectrom Ion Phys 5(1-2):137. https://doi. org/10.1016/0020-7381(70)87012-7

96. Balamuta J, Golde MF, Ho Y-S (1983) J Chem Phys 79(6):2822. https://doi.org/10.1063/1.446103

97. Thomas RD, Kashperka I, Vigren E, Geppert WD, Hamberg M, Larsson M, af Ugglas M, Zhaunerchyk V, Indriolo N, Yagi K, Hirata S, McCall BJ (2012) Astrophys J 758(1):55. https://doi. org/10.1088/0004-637X/758/1/55

98. Mitchell JBA (1990) Phys Rep 186(5):215. https://doi.org/10.1016/0370-1573(90)90159-Y

99. Mul PM, Mitchell JBA, D’Angelo VS, Defrance P, McGowan JW, Froelich HR (1981) J Phys B At Mol Phys 14(8):1353. https://doi.org/10.1088/0022-3700/14/8/020

100. Bates DR (1986) Astrophys J 306:L45. https://doi.org/10.1086/184702

101. Adams NG, Smith D (1988) Chem Phys Lett 144(1):11. https://doi.org/10.1016/0009-2614(88)87081 $-7$

102. Geppert W, Ehlerding A, Hellberg F, Kalhori S, Thomas RD, Novotny O, Arnold ST, Miller TM, Viggiano AA, Larsson M (2004) Phys Rev Lett 93:153201. https://doi.org/10.1103/PhysRevLet t.93.153201

103. Bates DR (1989) Astrophys J 344:531. https://doi.org/10.1086/167823

104. Ehlerding A, Hellberg F, Thomas R, Kalhori S, Viggiano AA, Arnold ST, Larsson M, af Ugglas M (2004) Phys Chem Chem Phys 6:949. https://doi.org/10.1039/B314882C

105. Mul PM, McGowan JW (1980) Astrophys J 237:749. https://doi.org/10.1086/157921

106. Kalhori S, Viggiano AA, Arnold ST, Rosén S, Semaniak J, Derkatch AM, af Ugglas M, Larsson M (2002) Astron Astrophys 391(3):1159. https://doi.org/10.1051/0004-6361:20020882

107. Derkatch AM, Al-Khalili A, Vikor L, Neau A, Shi W, Danared H, af Ugglas M, Larsson M (1999) J Phys B At Mol Opt Phys 32(14):3391. https://doi.org/10.1088/0953-4075/32/14/309

108. Mitchell JBA, McGowan JW (1978) Astrophys J 222:L77. https://doi.org/10.1086/182696

109. Hus H, Yousif F, Noren C, Sen A, Mitchell JBA (1988) Phys Rev Lett 60:1006. https://doi. org/10.1103/PhysRevLett.60.1006

110. Moseley J, Aberth W, Peterson JR (1970) Phys Rev Lett 24:435. https://doi.org/10.1103/PhysRevLet t.24.435

111. Baggott JE, Blitz MA, Frey HM, Lightfoot PD, Walsh R (1987) Chem Phys Lett 135(1):39. https:// doi.org/10.1016/0009-2614(87)87213-5

112. Shimo N, Nakashima N, Yoshihara K (1986) Chem Phys Lett 125(3):303. https://doi. org/10.1016/0009-2614(86)87070-1

113. Safarik I, Jodhan A, Strausz OP, Bell TN (1987) Chem Phys Lett 142(1):115. https://doi. org/10.1016/0009-2614(87)87262-7

114. Kerst C, Potzinger P, Wagner HG (1995) J Photochem Photobiol A Chem 90(1):19. https://doi. org/10.1016/1010-6030(95)04086-U

115. Niiranen JT, Gutman D (1993) J Phys Chem 97(37):9392. https://doi.org/10.1021/j100139a023

116. Tokach SK, Koob RD (1980) J Phys Chem 84(1):1. https://doi.org/10.1021/j100438a001

117. Ahmed M, Potzinger P, Wagner HG (1995) J Photochem Photobiol A Chem 86(1-3):33. https://doi. org/10.1016/1010-6030(94)03953-R

118. Kerst C, Potzinger P, Wagner HG (1996) Z Naturforsch 51A(1-2):105. https://doi.org/10.1515/ zna-1996-1-216

119. Ellul R, Potzinger P, Reimann B (1984) J Phys Chem 88(13):2793. https://doi.org/10.1021/j1506 $57 \mathrm{a} 024$

120. Baggott JE, Blitz MA, Frey HM, Walsh R (1990) J Am Chem Soc 112(23):8337. https://doi. org/10.1021/ja00179a018

121. Baggott JE, Blitz MA, Frey HM, Lightfoot PD, Walsh RR (1988) J Chem Soc Faraday Trans 2 84:515. https://doi.org/10.1039/F29888400515 
122. Brix T, Arthur NL, Potzinger P (1989) J Phys Chem 93(25):8193. https://doi.org/10.1021/j100362a01 1

123. Kerst C, Potzinger P, Wagner HG (1996) Z Naturforsch 51A(1-2):102. https://doi.org/10.1515/ zna-1996-1-215

124. Fabry L, Potzinger P, Reimann B, Ritter A, Steenbergen HP (1986) Organometallics 5(6):1231. https ://doi.org/10.1021/om00137a030

125. Canosa A, Le Picard SD, Gougeon S, Rebrion-Rowe C, Travers D, Rowe BR (2001) J Chem Phys 115(14):6495. https://doi.org/10.1063/1.1396855

126. Baulch DL, Cobos CJ, Cox RA, Frank P, Hayman G, Just T, Kerr JA, Murrells T, Pilling MJ, Troe J, Walker RW, Warnatz J (1994) J Phys Chem Ref Data 23(6):847. https://doi.org/10.1063/1.555953

127. Baulch DL, Cobos CJ, Cox RA, Frank P, Hayman G, Just T, Kerr JA, Murrells T, Pilling MJ, Troe J, Walker RW, Warnatz J (1995) J Phys Chem Ref Data 24(4):1609. https://doi.org/10.1063/1.555975

128. Wang B, Fockenberg C (2001) J Phys Chem A 105(37):8449. https://doi.org/10.1021/jp011350q

129. Galland N, Caralp F, Hannachi Y, Bergeat A, Loison J-C (2003) J Phys Chem A 107(28):5419. https ://doi.org/10.1021/jp027465r

130. Opansky BJ, Leone SR (1996) J Phys Chem 100(12):4888. https://doi.org/10.1021/jp9532677

131. Matsugi A, Suma K, Miyoshi A (2010) J Phys Chem A 114(13):4580. https://doi.org/10.1021/jp101 2494

132. Blitz MA, Johnson DG, Pesa M, Pilling MJ, Robertson SH, Seakins PW (1997) J Chem Soc Faraday Trans 93:1473. https://doi.org/10.1039/A607617C

133. Opansky BJ, Leone SR (1996) J Phys Chem 100(51):19904. https://doi.org/10.1021/jp9619604

134. Pasternack L, McDonald JR (1979) Chem Phys 43(2):173. https://doi.org/10.1016/03010104(79)85185-X

135. Tsang W, Hampson RF (1986) J Phys Chem Ref Data 15(3):1087. https://doi.org/10.1063/1.555759

136. Nakajima M, Matsugi A, Miyoshi A (2009) J Phys Chem A 113(31):8963. https://doi.org/10.1021/ jp904165s

137. Zabarnick S, Fleming JW, Lin MC (1986) J Chem Phys 85(8):4373. https://doi.org/10.1063/1.451808

138. Braun W, McNesby JR, Bass AM (1967) J Chem Phys 46(6):2071. https://doi.org/10.1063/1.1841003

139. Fulle D, Hippler H (1997) J Chem Phys 106(21):8691. https://doi.org/10.1063/1.473930

140. Harding LB, Guadagnini R, Schatz GC (1993) J Phys Chem 97(21):5472. https://doi.org/10.1021/ j100123a005

141. Martinotti FF, Welch MJ, Wolf AP (1968) Chem Commun (Lond) 115-116. https://doi.org/10.1039/ C19680000115

142. Pedley JB, Rylance J (1977) Sussex-N.P.L. Computer analysed thermochemical data: organic and organometallic compounds. University of Sussex, Brighton, England

143. Pitt CG, Bursey MM, Rogerson PF (1970) J Am Chem Soc 92(3):519. https://doi.org/10.1021/ja007 $06 \mathrm{a} 016$

144. Hosomi A, Traylor TG (1975) J Am Chem Soc 97(13):3682. https://doi.org/10.1021/ja00846a020

145. Davidson IMT, Stephenson IL (1967) J Organometal Chem 7(2):P24. https://doi.org/10.1016/S0022 $-328 \mathrm{X}(00) 91064-7$

146. Szepes L, Baer T (1984) J Am Chem Soc 106(2):273. https://doi.org/10.1021/ja00314a002

147. Davidson IMT, Potzinger P, Reimann B (1982) Ber Bunsenges Phys Chem 86(1):13. https://doi. org/10.1002/bbpc. 19820860104

148. Genchel' VG, Demidova NV, Nametkin NS, Gusel'nikov LE, Volnina EA, Burdasov EN, Vdovin VM (1976) Russ Chem Bull 25(10):2181. https://doi.org/10.1007/BF02659543

149. Pitt CG, Habercom MS, Bursey MM, Rogerson PF (1968) J Organometal Chem 15(2):359. https:// doi.org/10.1016/S0022-328X(00)91314-7

150. Walsh R (1989) Organometallics 8(8):1973. https://doi.org/10.1021/om00110a021

151. Potzinger P, Ritter A, Krause J, Naturforsch Z A (1975) 30:347. https://doi.org/10.1515/ zna-1975-0314

152. Hess GG, Lampe FW, Sommer LH (1965) J Am Chem Soc 87(23):5327. https://doi.org/10.1021/ ja00951a012

153. Chase MW (1998) Phys J, Chem. Ref. Data Monograph 9, 1. NIST-JANAF Thermochemical Tables, 4th edn. Part I, Al-Co

154. Murphy MK, Beauchamp JL (1977) J Am Chem Soc 99(7):2085. https://doi.org/10.1021/ja00449a01 3

155. Allendorf MD, Melius CF (1992) J Phys Chem 96(1):428. https://doi.org/10.1021/j100180a080

156. Wetzel DM, Brauman JI (1988) J Am Chem Soc 110(25):8333. https://doi.org/10.1021/ja00233a008

157. Coote ML, Lin CY, Beckwith ALJ, Zavitsas AA (2010) Phys Chem Chem Phys 12:9597. https://doi. org/10.1039/C003880F 
158. Davidson IMT, Stephenson IL (1968) J Chem Soc A. 282. https://doi.org/10.1039/J19680000282

159. Doncaster AM, Walsh R (1986) J Chem Soc Faraday Trans 2 82:707. https://doi.org/10.1039/F2986 8200707

160. Band SJ, Davidson IMT, Lambert CA, Stephenson IL (1967) Chem Commun (Lond) 723. https://doi. org/10.1039/C19670000723

161. Dyke JM, Josland GD, Lewis RA, Morris A (1982) J Phys Chem 86(15):2913. https://doi. org/10.1021/j100212a022

162. Casserly TB, Gleason KK (2005) Plasma Process Polym 2(9):669. https://doi.org/10.1002/ ppap. 200500054

163. Brinkman EA, Berger S, Brauman JI (1994) J Am Chem Soc 116(18):8304. https://doi.org/10.1021/ ja00097a042

164. Chatgilialoglu C (1995) Chem Rev 95(5):1229. https://doi.org/10.1021/cr00037a005

165. Davidson IMT, Matthews JI (1976) J Chem Soc Faraday Trans 1 72:1403. https://doi.org/10.1039/ F19767201403

166. Ketvirtis AE, Bohme DK, Hopkinson AC (1995) J Phys Chem 99(43):16121. https://doi.org/10.1021/ j100043a063

167. Walsh R (1988) Organometallics 7(1):75. https://doi.org/10.1021/om00091a014

168. Bengali AA, Leopold DG (1992) J Am Chem Soc 114(23):9192. https://doi.org/10.1021/ja00049a064

169. Chase MW (1998) Phys J Chem. Ref. Data Monograph 9, 959. NIST-JANAF Thermochemical Tables, 4th edn. Part II, Cr-Zr

170. Scheer M, Bilodeau RC, Brodie CA, Haugen HK (1998) Phys Rev A 58:2844. https://doi. org/10.1103/PhysRevA.58.2844

171. Pittam DA, Pilcher G (1972) J Chem Soc Faraday Trans 1 68:2224. https://doi.org/10.1039/F1972 6802224

172. Rosenstock HM, Draxl K, Steiner BW, Herron JT (1977) J Phys Chem Ref Data 6(Suppl. 1):1

173. Prosen EJ, Maron FW, Rossini FD (1951) J Res NBS 46(2):106. https://nvlpubs.nist.gov/nistpubs/ jres/46/jresv46n2p106_A1b.pdf

174. van der Meij CE, van Eck J, Niehaus A (1989) Chem Phys 130(1):325. https://doi. org/10.1016/0301-0104(89)87061-2

175. Mallard WG, Miller JH, Smyth KC (1983) J Chem Phys 79(12):5900. https://doi. org/10.1063/1.445770

176. Stockbauer R, Inghram MG (1971) J Chem Phys 54(5):2242. https://doi.org/10.1063/1.1675158

177. Furuyama S, Golden DM, Benson SW (1969) J Chem Thermodyn 1(4):363. https://doi. org/10.1016/0021-9614(69)90066-4

178. Traeger JC (1984) Int J Mass Spectrom Ion Process 58:259. https://doi.org/10.1016/0168$1176(84) 80034-8$

179. Manion JA (2002) J Phys Chem Ref Data 31(1):123. https://doi.org/10.1063/1.1420703

180. Luo Y-R, Pacey PD (1992) Int J Mass Spectrom Ion Process 112(1):63. https://doi. org/10.1016/0168-1176(92)87032-A

181. Berkowitz J, Ellison GB, Gutman D (1994) J Phys Chem 98(11):2744. https://doi.org/10.1021/ j100062a009

182. DePuy CH, Gronert S, Barlow SE, Bierbaum VM, Damrauer R (1989) J Am Chem Soc 111(6):1968. https://doi.org/10.1021/ja00188a003

183. DeFrees DJ, McIver RT, Hehre WJ (1980) J Am Chem Soc 102(10):3334. https://doi.org/10.1021/ ja00530a005

184. Ervin KM, Gronert S, Barlow SE, Gilles MK, Harrison AG, Bierbaum VM, DePuy CH, Lineberger WC, Ellison GB (1990) J Am Chem Soc 112(15):5750. https://doi.org/10.1021/ja001 $71 \mathrm{a} 013$

185. Blush JA, Chen P (1992) J Phys Chem 96(11):4138. https://doi.org/10.1021/j100190a004

186. Norwood K, Ng CY (1989) J Chem Phys 91(5):2898. https://doi.org/10.1063/1.456960

187. Arnold DW, Bradforth SE, Kitsopoulos TN, Neumark DM (1991) J Chem Phys 95(12):8753. https ://doi.org/10.1063/1.461211

188. Reid CJ, Ballantine JA, Andrews SR, Harris FM (1995) Chem Phys 190(1):113. https://doi. org/10.1016/0301-0104(94)00335-8

189. Berkowitz J, Greene JP, Cho H, Ruscić B (1987) J Chem Phys 86(2):674. https://doi. org/10.1063/1.452268

190. Ellison GB, Engelking PC, Lineberger WC (1978) J Am Chem Soc 100(8):2556. https://doi. org/10.1021/ja00476a054

191. Leopold DG, Murray KK, Miller AES, Lineberger WC (1985) J Chem Phys 83(10):4849. https:// doi.org/10.1063/1.449746 
192. Goebbert DJ (2012) Chem Phys Lett 551:19. https://doi.org/10.1016/j.cplett.2012.08.065

193. Herzberg G, Johns JWC (1969) Astrophys J 158:399. https://doi.org/10.1086/150202

194. Bird RB, Stewart WE, Lightfoot EN (1960) Transport phenomena. Wiley, New York

195. Fuller EN, Schettler PD, Giddings JC (1966) Ind Eng Chem 58(5):19. https://doi.org/10.1021/ ie $50677 \mathrm{a} 007$

196. Fuller EN, Ensley K, Giddings JC (1969) J Phys Chem 73(11):3679. https://doi.org/10.1021/j1008 $45 \mathrm{a} 020$

197. Hirschfelder JO, Bird RB, Spotz EL (1949) Chem Rev 44(1):205. https://doi.org/10.1021/cr601 $37 \mathrm{a} 012$

198. https://www.lookchem.com (2019). CAS Nos. 106-98-9, 106-99-0, 812-15-7, 814-98-2, 1627-981, 2117-28-4, 3439-38-1, 3704-44-7, 15063-64-6

199. Marcos DH, Lindley DD, Wilson KS, Kay WB, Hershey HC (1983) J Chem Thermodyn 15(11):1003. https://doi.org/10.1016/0021-9614(83)90024-1

200. Schön H (2015) Handbook of purified gases. Springer, Berlin. https://doi.org/10.1007/978-3-54032599-4

201. L'vov BV, Nikolaev VG (1987) J Appl Spectrosc 46(1):1. https://doi.org/10.1007/BF00660271

202. Shevla RA (1962) Estimated viscosities and thermal conductivities of gases at high temperatures. Tech. Rep. NASA TR R-132, National Aeronautics and Space Administration, Cleveland, Ohio

203. Institut für Arbeitsschutz der Deutschen Gesetzlichen Unfallversicherung. http://gestis.itrust.de (2018)

204. Smit B, Karaborni S, Siepmann JI (1995) J Chem Phys 102(5):2126. https://doi.org/10.1063/1.46956 3

205. Moore CE (1949) Atomic energy levels vol. 1. Tech. Rep. NBS Circular 467, US Government Printing Office, Washington

206. Ashpis DE, Laun MC, Griebeler EL (2017) AIAA J 55(7):2254. https://doi.org/10.2514/1.J055816

207. Sawada Y, Ogawa S, Kogoma M (1995) J Phys D Appl Phys 28(8):1661. https://doi. org/10.1088/0022-3727/28/8/015

208. Morent R, De Geyter N, Van Vlierberghe S, Dubruel P, Leys C, Gengembre L, Schacht E, Payen E (2009) Prog Org Coat 64(2-3):304. https://doi.org/10.1016/j.porgcoat.2008.07.030

209. Morent R, De Geyter N, Van Vlierberghe S, Dubruel P, Leys C, Schacht E (2009) Surf Coat Technol 203(10-11):1366. https://doi.org/10.1016/j.surfcoat.2008.11.008

210. Morent R, De Geyter N, Jacobs T, Van Vlierberghe S, Dubruel P, Leys C, Schacht E (2009) Plasma Process Polym 6(S1):S537. https://doi.org/10.1002/ppap.200931101

211. Bröcker L, Perlick GS, Klages C-P (2020) Plasma Process Polym e2000129. https://doi.org/10.1002/ ppap.202000129

212. Loffhagen D, Becker MM, Czerny AK, Klages C-P (2020) Electrical characteristics of atmosphericpressure DBD in argon with small admixtures of TMS - measured and calculated data. https://doi. org/10.34711/inptdat.250

Publisher's Note Springer Nature remains neutral with regard to jurisdictional claims in published maps and institutional affiliations. 